\title{
Assessing transportation vulnerability to tsunamis: utilising post-event field data from the 2011 Tōhoku tsunami, Japan, and the 2015 Illapel tsunami, Chile
}

\author{
James H. Williams ${ }^{1}$, Thomas M. Wilson ${ }^{1}$, Nick Horspool ${ }^{2}$, Ryan Paulik ${ }^{3}$, Liam Wotherspoon ${ }^{4}$, Emily M. Lane ${ }^{5}$, and \\ Matthew W. Hughes ${ }^{6}$ \\ ${ }^{1}$ School of Earth and Environment, University of Canterbury, Christchurch, 8041, New Zealand \\ ${ }^{2}$ GNS Science, Lower Hutt, 5040, New Zealand \\ ${ }^{3}$ National Institute of Water and Atmospheric Research, Wellington, 6021, New Zealand \\ ${ }^{4}$ Department of Civil and Environmental Engineering, University of Auckland, Auckland, 1010, New Zealand \\ ${ }^{5}$ National Institute of Water and Atmospheric Research, Christchurch, 8011, New Zealand \\ ${ }^{6}$ Department of Civil and Natural Resources Engineering, University of Canterbury, Christchurch, 8041, New Zealand
}

Correspondence: James H. Williams (james.williams@pg.canterbury.ac.nz)

Received: 9 October 2019 - Discussion started: 16 October 2019

Revised: 9 January 2020 - Accepted: 21 January 2020 - Published: 19 February 2020

\begin{abstract}
Transportation infrastructure is crucial to the operation of society, particularly during post-event response and recovery. Transportation assets, such as roads and bridges, can be exposed to tsunami impacts when near the coast. Using fragility functions in an impact assessment identifies potential tsunami effects to inform decisions on potential mitigation strategies. Such functions have not been available for transportation assets exposed to tsunami hazard in the past due to limited empirical datasets. This study provides a suite of observations on the influence of tsunami inundation depth, road-use type, culverts, inundation distance, debris and coastal topography. Fragility functions are developed for roads, considering inundation depth, road-use type, and coastal topography and, for bridges, considering only inundation depth above deck base height. Fragility functions are developed for roads and bridges through combined survey and remotely sensed data for the 2011 Tōhoku earthquake and tsunami, Japan, and using post-event field survey data from the 2015 Illapel earthquake and tsunami, Chile. The fragility functions show a trend of lower tsunami vulnerability (through lower probabilities of reaching or exceeding a given damage level) for road-use categories of potentially higher construction standards. The topographic setting is also shown to affect the vulnerability of transportation assets in a tsunami, with coastal plains seeing higher initial vulnera-
\end{abstract}

bility in some instances (e.g. for state roads with up to $5 \mathrm{~m}$ inundation depth) but with coastal valleys (in some locations exceeding $30 \mathrm{~m}$ inundation depth) seeing higher asset vulnerability overall. This study represents the first peer-reviewed example of empirical road and bridge fragility functions that consider a range of damage levels. This suite of synthesised functions is applicable to a variety of exposure and attribute types for use in global tsunami impact assessments to inform resilience and mitigation strategies.

\section{Introduction}

Road networks are critical to the every-day operation of society as well as to the response and recovery phases posttsunami. Access to impacted populations and repair works to other lifelines can be delayed by roads that are damaged or have reduced levels of service (Eguchi et al., 2013; Horspool and Fraser, 2016; Koks et al., 2019; Nakanishi et al., 2014; Williams et al., 2019). Observations from previous international tsunamis have recorded widespread damage and loss of service to transportation assets, including from the 2004 Indian Ocean tsunami and the 2010 Maule tsunami, Chile (Ballantyne, 2006; Edwards, 2006; Evans and McGhie, 2011; Fritz et al., 2011; Goff et al., 2006; Lin et 
al., 2019; Palliyaguru and Amaratunga, 2008; Paulik et al., 2019; Scawthorn et al., 2006; Tang et al., 2006). Defining road asset vulnerability to tsunamis is important for impact assessment and evaluation of mitigation strategies to reduce potential impacts on road networks. In order to do this, robust tsunami vulnerability metrics are required.

Current scientific literature has focused on the development of tsunami vulnerability metrics for damage to buildings (e.g. Aránguiz et al., 2018; Suppasri et al., 2013), which provide a measure of damage or loss for a prescribed hazard intensity. There are few comparable examples for tsunami damage to lifeline infrastructure components (e.g. Horspool and Fraser, 2016; Williams et al., 2019). Commonly used metrics include vulnerability and fragility functions, which are used to define the relationship between asset impact level and a hazard intensity (e.g. tsunami inundation depth; Koshimura et al., 2009). Vulnerability functions define the probability of losses (e.g. economic losses) for the given hazard intensity measure, whereas fragility functions provide the probability of exceeding different limit states (e.g. physical damage) for the given hazard intensity measure (Lagomarsino and Cattari, 2015). Fragility functions typically rely on relatively large samples of empirical or modelled impact data, yet quantitative data for road vulnerability have been unavailable prior to recent tsunami disasters. Fragility functions derived from a single tsunami event means they will be characteristic of local asset and event characteristics. For transportation assets, only bridge structures have been analysed for fragility function development (Kawashima and Buckle, 2013; Koks et al., 2019; Shoji and Moriyama, 2007). These studies applied tsunami inundation depth as the hazard intensity measure (HIM), as it usually has a strong correlation with impact and is relatively easy both to model and to measure post-disaster. However tsunami hazard and impact studies to date are almost unanimous in that no single HIM can fully encapsulate the characteristics of tsunami impacts (Bojorquez et al., 2012; Gehl and D'Ayala, 2015; Macabuag et al., 2017; Sousa et al., 2014).

Although post-event tsunami surveys commonly record road impacts as physical damage levels, levels of service can also be considered, which include but are not limited to physical damage. Coastal road networks are most commonly damaged or totally destroyed, either by debris impact or erosion of the substrate material (Eguchi et al., 2013; Horspool and Fraser, 2016; Kawashima and Buckle, 2013; Kazama and Noda, 2012; MLIT, 2012), and have reduced levels of service due to debris litter (Evans and McGhie, 2011). Debris litter is a widely identified post-event impact that affects the functionality of an otherwise undamaged road. Prasetya et al. (2012) and Naito et al. (2014) modelled debris transport pathways and the debris impact zone potential, respectively, with the first noting that debris further inland results in the greatest disruption to lifelines. Neither study assessed debris density probability for tsunami. Evans and McGhie (2011) note a correlation between debris sizes as a function of inun- dation depth to measure spatial distribution; however deposition was not assessed.

Tsunami damage cannot be fully characterised by any one HIM. The topographic setting can also potentially be used to define variations in tsunami damage characteristics. When a tsunami wave reaches the coast, it will travel either long distances inland, at relatively low inundation depths over planar topography, or, if confined near the coast, will reach considerably greater inundation depths. Planar topography will result in lower retreating inundation speeds, whilst the opposite is likely for areas of steep coastal topography (Naito et al., 2014; De Risi et al., 2017; Suppasri et al., 2013).

The objectives of the current study are (a) to analyse postevent tsunami survey data to identify potential characteristics of tsunami impacts on road network assets and (b) to develop a suite of tsunami fragility functions for transportation infrastructure assets. This study analyses road asset damage data from two recent tsunamis, the 2011 Tōhoku earthquake and tsunami, Japan, and the 2015 Illapel earthquake and tsunami, Chile. This addresses the gap in global knowledge of tsunami impacts on transportation infrastructure and ultimately informs tsunami risk reduction. Other than the economic and strategic value that transportation networks provide in postevent response and recovery, transportation assets were selected for the focus of this paper due to them having the only consistently available asset data between the two events. This is in part due to the willingness of organisations to share their network damage data and due to the readily observed assets in field, which are not obvious for the likes of buried infrastructure (e.g. pipes and cables). The data are analysed considering a range of novel hazard intensity proxies (e.g. distance from coastline) to encapsulate a wider range of HIMs. This better represents road vulnerability to tsunami impacts than using a measure of inundation depth alone.

The $M_{\mathrm{w}} 9.0$ Tōhoku earthquake in the Pacific Ocean, east of Japan (Fig. 1b), caused tsunami waves exceeding $30 \mathrm{~m}$ inundation depth, in some extreme cases, and affected much of Japan's eastern coast, which was also earthquake-affected (MLIT, 2012). Transportation infrastructure were extensively damaged throughout the exposed region during this event (Eguchi et al., 2013; Graf et al., 2014; MLIT, 2012). The Illapel event took place on 16 September 2015 in northerncentral Chile, triggered by a $M_{\mathrm{w}} 8.3$ earthquake off the coast of the Talinay Peninsula (Fig. 1a; Aránguiz et al., 2016, 2018; Contreras-López et al., 2016; Izquierdo et al., 2018; Ye et al., 2015). This event caused localised inundation of up to $7 \mathrm{~m}$, with severe impacts to the transportation infrastructure, the greatest of which were in Coquimbo. While the Tohoku dataset represents the largest tsunami damage survey for roads, the Illapel dataset represents the first known census-style survey of roads impacted by tsunamis. All exposed assets in the Illapel study area (Fig. 1a) were surveyed, not only those with observed damage, which was not the case following the Tōhoku event. 


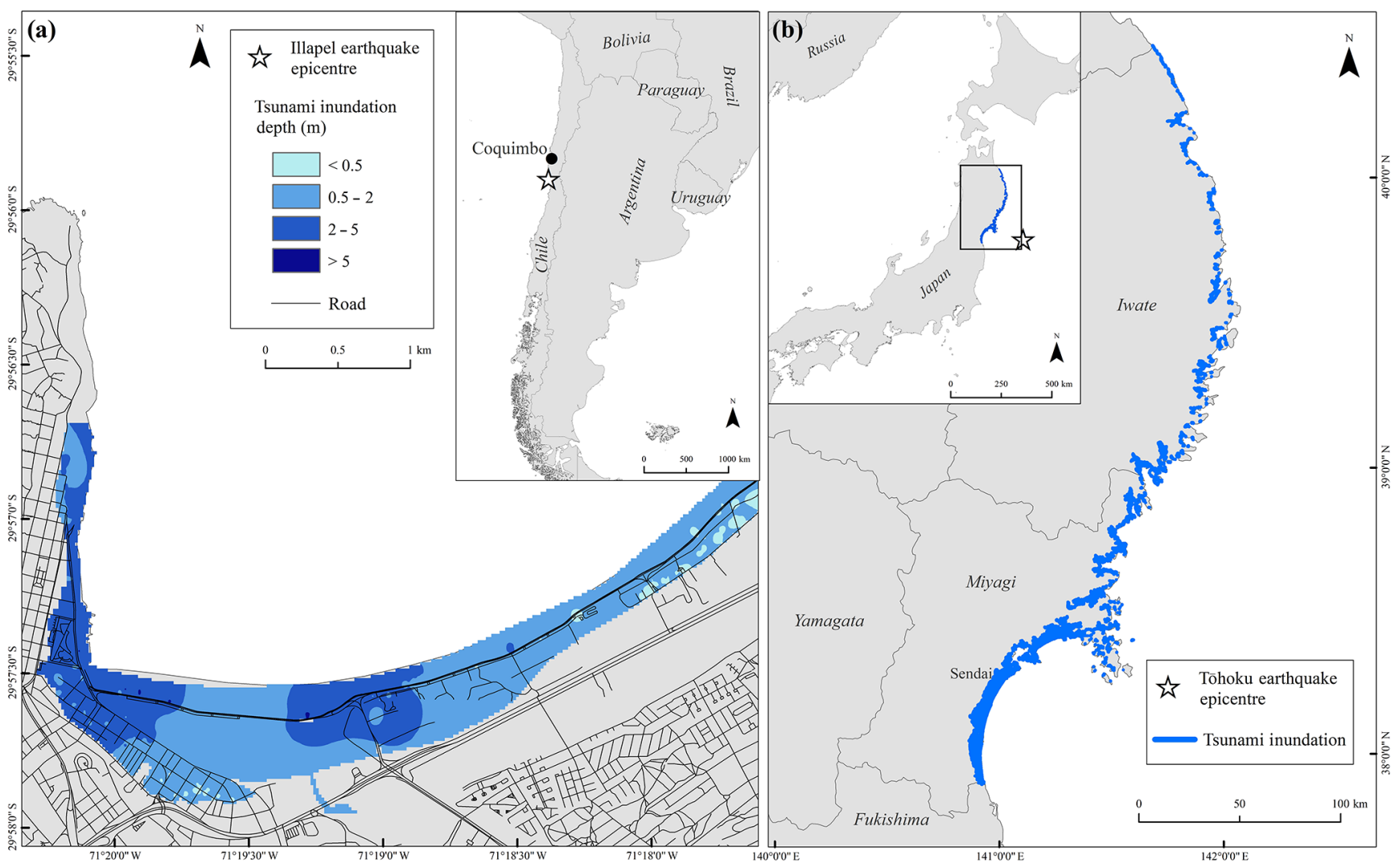

Figure 1. Tsunami inundation in Coquimbo for the 2015 Illapel tsunami, Chile (a), and in Miyagi and Iwate prefectures for the 2011 Tōhoku tsunami, Japan (b). (C) OpenStreetMap contributors 2015. Distributed under a Creative Commons BY-SA License.

The Tōhoku data analysed in this study were obtained during field surveys and compiled by the Ministry of Land Infrastructure, Transportation and Tourism (MLIT), whereas the authors collected the Illapel data (Sect. 2.1). Road and bridge damage and tsunami inundation depth were used to derive vulnerability functions using least-squares regression and log-normal probability density functions. The tsunami inundation depth for each asset was obtained by remotely assigning interpolated depth values from the respective surveys (Sect. 2.1). The data were first analysed for all assets (mixed construction; Sect. 2.2) and then split between use type (as a proxy for construction material; Sect. 2.2.1), distance from the coast (as a proxy for inundation energy; Sect. 2.2.2), and distance from the inland extent of inundation (Sect. 2.2.3), coastal topography (Sect. 2.2.4), to capture and identify potential variations in asset damage and service levels. Although each analysis gives insight into the broader picture of tsunami impacts on transportation assets, not all data were applicable to the development of fragility functions.

The following sections present the two event datasets, noting a range of hazard-impact trends and observations in the data, which are supplemented with remotely sensed asset and hazard data (Sect. 2). This includes any trends in the data for topographic setting and asset use type. The results (Sect. 3) of the analysis are then presented as a suite of vulnerability functions for each applicable hazard-intensity and asset-type combination. A discussion (Sect. 4) on the results is then presented, which includes their limitations, potential applications and recommendations for future studies, followed by the conclusions of the study.

\section{Methodology}

\subsection{Data collection}

\subsubsection{Event 1: Tōhoku earthquake and tsunami}

The Tōhoku earthquake and tsunami provided post-disaster survey teams with an extensive area from which to collect damage data on infrastructure assets. The data used for this analysis are the results of a comprehensive ground survey carried out in the days and weeks following the tsunami by the Japanese Government, City Bureau of the Ministry of Land, Infrastructure, Transport and Tourism (MLIT, 2012). The data relevant to this analysis included detailed road asset damage summaries and local maximum tsunami inundation depths for the exposed area within the Miyagi and Iwate prefectures, which were two of the regions most impacted 
(Eguchi et al., 2013; Horspool and Fraser, 2016; MLIT, 2012; Kazama and Noda, 2012; Fig. 1). MLIT defined the length of affected roads and assigned each section a damage level (Table 1). Much of the study area experienced high levels of long-duration shaking, so not all of the observed damage is necessarily exclusive to tsunami processes (Shoji and Nakamura, 2014). However, it is widely reported in literature and through eyewitness accounts that, in most cases, damage to tsunami-exposed assets was more characteristic of tsunami impacts than with ground shaking. Despite this, some assets would have been damaged, or completely destroyed, by initial earthquake shaking, and this co-seismic damage is not recorded in the survey data. Areas with flat topography are not typically consistent with direct road damage from shaking alone. However, where soil liquefaction occurred, this could have resulted in damage, which is not accounted for in this study. The inundation depth and asset data, containing the damage observations, were requested by, and presented to, GNS Science as GIS shapefiles (.shp). The asset data were presented as edges (lines), representing the true length of each damage observation recorded. The damage data were supplemented with a Japanese-to-English translated spreadsheet of instructions and explanations. Modelled maximum inundation depth $(\mathrm{m})$ was available in $100 \mathrm{~m} \times 100 \mathrm{~m}$ grid cells across the study area (Eguchi et al., 2013; MLIT, 2012; Horspool and Fraser, 2016). This empirical dataset is one of only few in existence globally for transportation damaged by tsunamis, which is why it is included for this study.

\subsubsection{Event 2: Illapel earthquake and tsunami}

A census-style field survey was conducted in Coquimbo, Chile, between 8 and $12 \mathrm{~d}$ after the Illapel event by a New Zealand-based team of five. The New Zealand Society for Earthquake Engineering requested and accepted an invitation from the Chilean Association of Seismology and Earthquake Engineering to undertake a collaborative field survey. The team included members from GNS Science, National Institute of Water and Atmospheric Research (NIWA), Wellington Lifelines Group, Auckland City Council, and University of Canterbury and was supported by Chilean researchers from Valparaiso University. Coquimbo was selected as the focus of the post-event survey, as it was the region most impacted in this event and also represented a small enough study area to collect data in a short timeframe. Damage, asset and hazard data were collected, using the Real-time Individual Asset Collection Tool (RiACT) in accordance with International Tsunami Survey Team (ITST) procedures (Lin et al., 2019). Observations were recorded as points, and in the case of roads, a point was placed in the centre of each observation with a length of observed damage also recorded, among other attributes.

The survey area experienced low peak ground accelerations (0.20-0.29 g; USGS, 2015) in this earthquake event, and subsequently road damage can be assumed to be only tsunami induced. This assumption was corroborated through informal discussion between the field survey team and members of the public. Road damage was defined using a fourtier damage-level classification in accordance with the MLIT classification structure (Table 1). This was done to be consistent with the Tōhoku dataset, which was already available and represented the largest damage repository of tsunami impacts on roads and bridges, as outlined in the subsection below. Although this classification of damage level could have been refined, the field team decided it still represented a relatively efficient method in field and at a resolution high enough to incorporate the range of observed damage types. Most roads in the inundation area were founded on sandy material, with a compacted granular subbase and a thin asphalt surface (flexible pavement construction method; Nunn et al., 1997; NZTA, 2014). There were few "both-lane" washouts, with minor or single lane washouts being more common, and many washouts occurred where a culvert ran beneath the road surface. Inundation depth indicators (watermarks) were also collected in the field by measuring watermarks against vertical structures (e.g. buildings, utility poles). A total of 978 watermarks were recorded across the survey area, which represented maximum inundation depth above ground level. The total survey area included an approximately $7 \mathrm{~km}$ stretch of coastline.

\subsection{Data analysis and damage observations}

The first step in defining vulnerability is to develop fragility functions, which require spatial hazard metrics (HIMs), measured or descriptive spatial asset data (both damaged and undamaged), and asset attribute information. The HIM and asset attribute information are the two key variables when considering vulnerability, and both are considered, independently and in tandem, to define vulnerability of assets. The most common HIM is inundation depth, and the first step was to use this data to calculate fragility functions for mixedconstruction assets. With the Coquimbo dataset, roads were separated into approximately $50 \mathrm{~m}$ sections and assigned the corresponding damage level (DL0-DL3) and inundation depth, through the watermark interpolation, at the centre of each feature (Fig. 2) using inundation depth bins of $0.25 \mathrm{~m}$ $(0.0-0.25,0.25-0.5 \mathrm{~m}$, etc.). The total length of road (in km) for each depth bin and for each damage level was tabulated for each HIM by count and proportion (Fig. 3). Once inundation depth had been considered, other HIMs were used to define vulnerability more holistically. Fragility functions were then developed, as described in more detail in Sect. 2.3.

The Tōhoku dataset lacked spatial undamaged asset data (DL0), which is crucial in defining proportional damage probabilities. Therefore, all roads within the inundation area were extracted from OpenStreetMap (OSM; OpenStreetMap contributors, 2015) or were digitised from aerial imagery, and those which were not recorded in the MLIT data were assumed undamaged (DL0). This resulted in a complete dataset 
Table 1. MLIT damage classifications for roads and bridges (MLIT, 2012) and field examples of road damage levels from the 2015 Illapel earthquake and tsunami, Coquimbo, Chile, and equivalent bridge examples from the 2018 Sulawesi earthquake and tsunami, Indonesia.

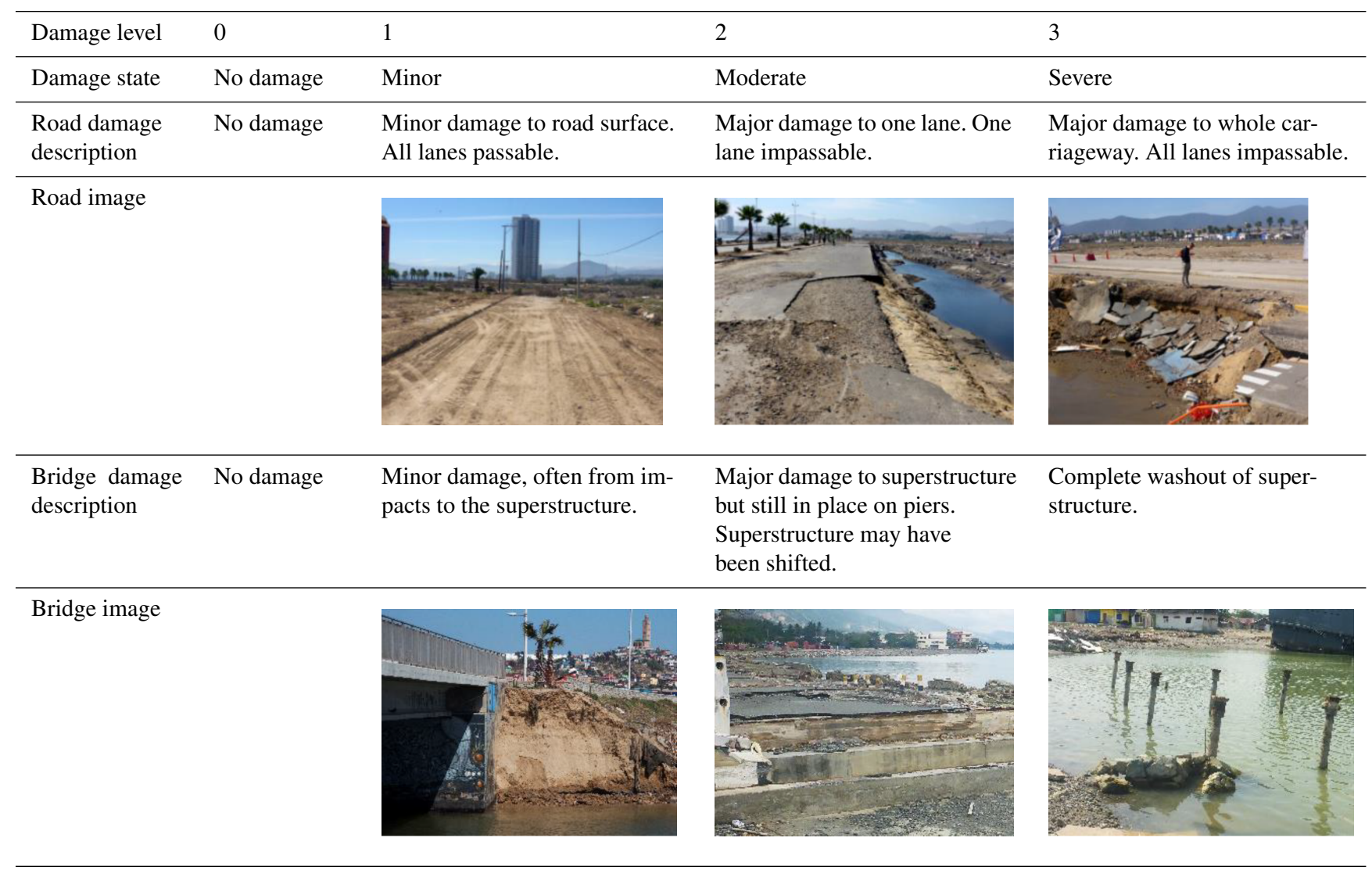

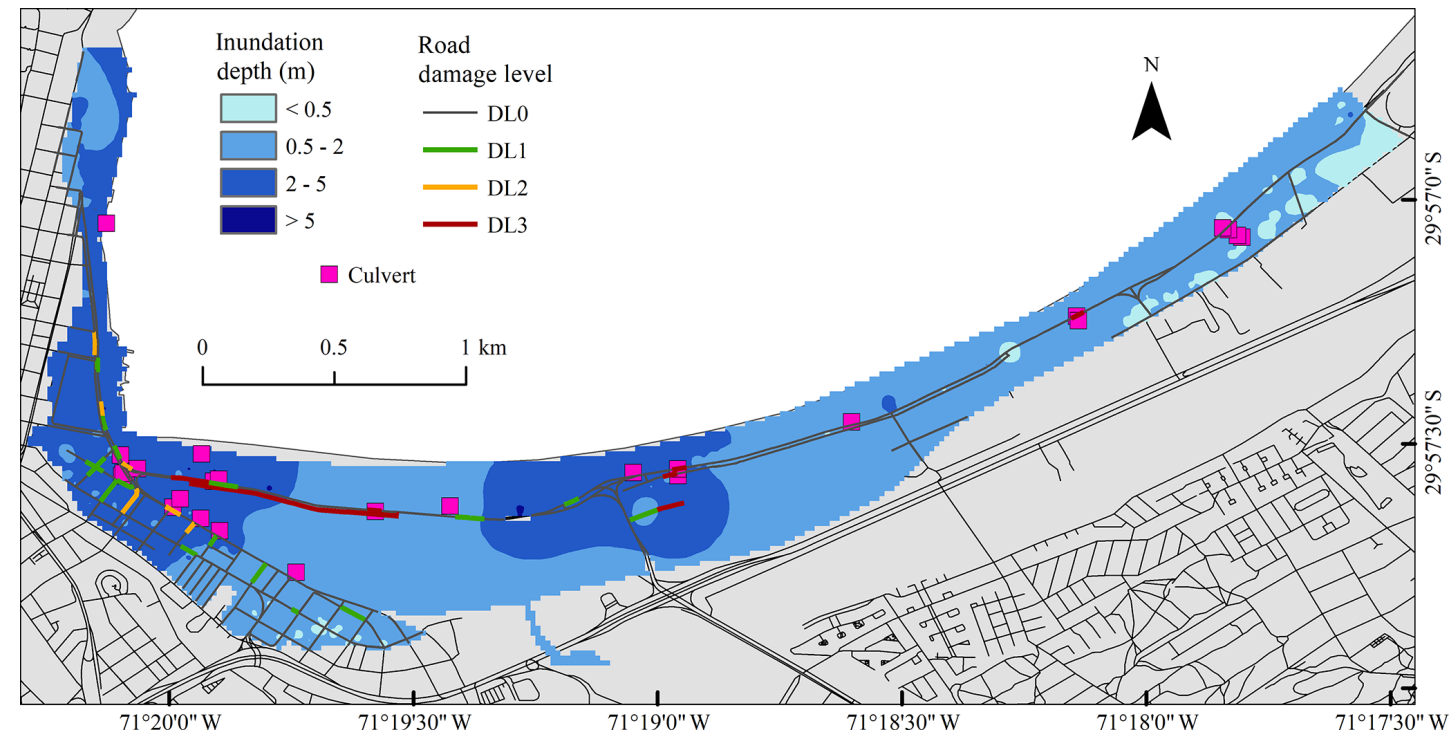

Figure 2. Tsunami inundation, road damage level and culvert locations in Coquimbo, Chile, following the 2015 Illapel earthquake and tsunami. (C) OpenStreetMap contributors 2015. Distributed under a Creative Commons BY-SA License. 

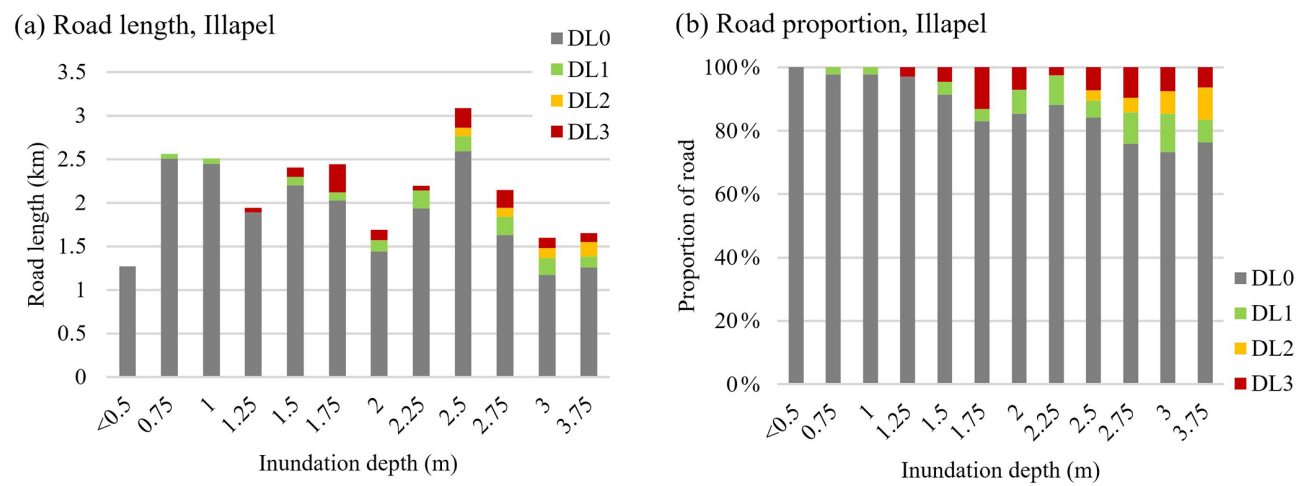

Figure 3. Total length (a) and proportion (b) of exposed roads, by inundation depth, for the 2015 Illapel earthquake and tsunami.

of roads and bridges exposed to the tsunami, each with an observed damage level (DL0-DL3). Figure 4 shows an example of observed damage levels for roads in the town of Ishinomaki within the study area. Tsunami inundation depths MLIT (2012) were then assigned to each road section using $1 \mathrm{~m}$ inundation depth bins (i.e. $0.0-1.0,1.0-2.0 \mathrm{~m}$, etc.). Larger inundation depth bins were used compared with the Illapel dataset (i.e. $1 \mathrm{~m}$ vs. $0.25 \mathrm{~m}$ ), as there were greater hazard intensity values ( $>10 \mathrm{~m}$ vs. $<4 \mathrm{~m}$ ). Road length totals in each hazard intensity bin were tabulated for each damage level) by count and proportion (Fig. 5). The results of this analysis are presented in Sect. 3 as fragility functions.

Asset attribute information should include road construction type, allowing for the development of construction specific fragility functions. As this was not included in the MLIT (2012) dataset, the closest equivalent was a road-usetype category based on jurisdiction ( 0 - unclassified; 1 - state road; 2 - main local road; 3 - general prefectural road; 4 municipality road; 5 - lowest-class road). These classifications were then converted to road-use-type equivalent categories $(0$ - unclassified; 1 - motorway, trunk, primary; 2 secondary; 3 - residential, road; 4 - tertiary; 5 - construction, service, unsurfaced) to ensure compatibility with OSM (OpenStreetMap contributors, 2015) data (DL0). Roads digitised from satellite imagery were assumed to be in class 3 . However, those that could not be classified were "unclassified" (0), which did not contribute towards the resulting fragility functions. These road-use classes link to different traffic loading levels, which inform road design; therefore these data broadly encompass differences in construction type, but some degree of overlap is assumed.

The analysis used for Tōhoku bridge vulnerability was similar to that of roads; however inundation depth was normalised to the height above the base of a bridge deck. OSM data already included bridges as a separate road attribute and so were easily integrated, and satellite imagery was used only to validate that all bridges were included. Neither bridge construction materials nor bridge deck base height above ground was available, both of which would be necessary for a higher-resolution fragility function (Horspool and Fraser, 2016; Shoji and Moriyama, 2007).

The MLIT dataset had an assigned bridge damage level between DL1 and DL3 (Table 1). All non-surveyed bridges in the inundation area were assumed to be undamaged and consequently assigned DL0. Figure 6 shows an example of observed damage levels for bridges in the town of Ishinomaki within the study area. Modelled tsunami inundation depth was assigned at the centre point of each bridge to avoid a bridge falling within multiple inundation depth bins. Since deck base height was not included in the dataset and in many cases the hazard layer did not include depths within river channels, to estimate the inundation depth above deck base height the inundation depth at the bridge abutment was used, and the assumption was made that in most cases the deck would be relatively level with the abutment, although the deck height (thickness of beams and roadway) is still not considered. Bridges in each hazard intensity bin were tabulated for each damage level by count and proportion (Fig. 5), and resulting fragility functions are presented in Sect. 3.

\subsubsection{Culverts associated with increased road impacts}

While inundation depth has been used as the HIM, as outlined above, other potential metrics that might have a bearing on asset vulnerability were also considered. As mentioned in Sect. 2.1, in Coquimbo, Chile, road damage was observed at many culvert openings, especially along the coastal esplanade (Fig. 2). This damage is consistent with the principle of contraction scour (Duc and Rodi, 2008), which occurs when the depth of inundation exceeds an opening and the inundation becomes contracted. The inundation is directed down and through the structure, causing an increase in the velocity and shear stress around the outlet, therefore increasing scour. Inundation speed, inundation depth, the degree of submersion and size of the culvert are all factors dictating contraction scour intensity. Scour can also be exacerbated by the enhanced turbulence and vortex formation in this inundation. Scour around culverts can also be caused by the back inundation after a tsunami has receded. Recorded culvert lo- 


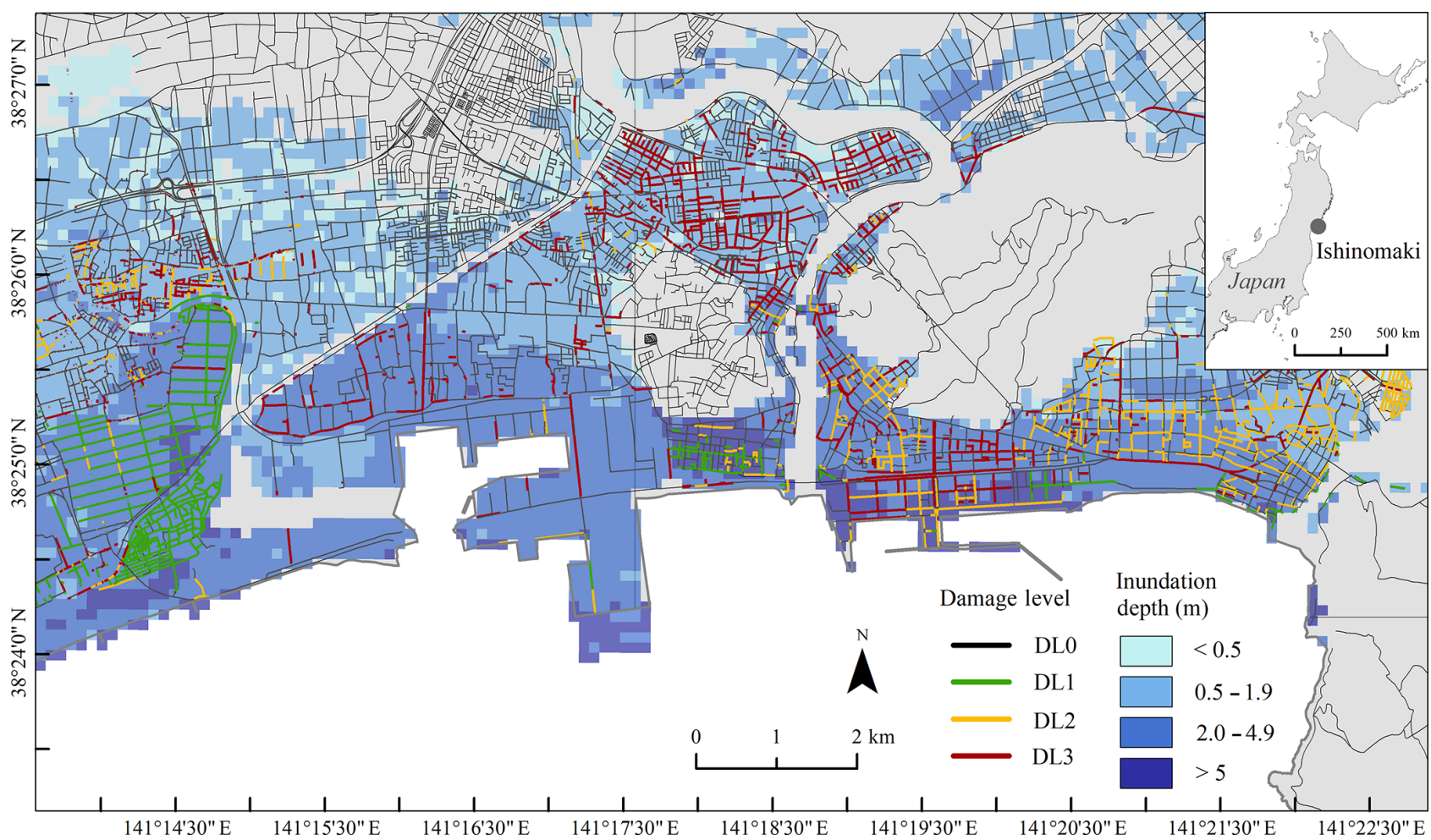

Figure 4. Tsunami inundation and road damage in Ishinomaki from the 2011 Tōhoku earthquake and tsunami, Japan. Road-impact data modified from MLIT, 2012. (C) OpenStreetMap contributors 2015. Distributed under a Creative Commons BY-SA License.
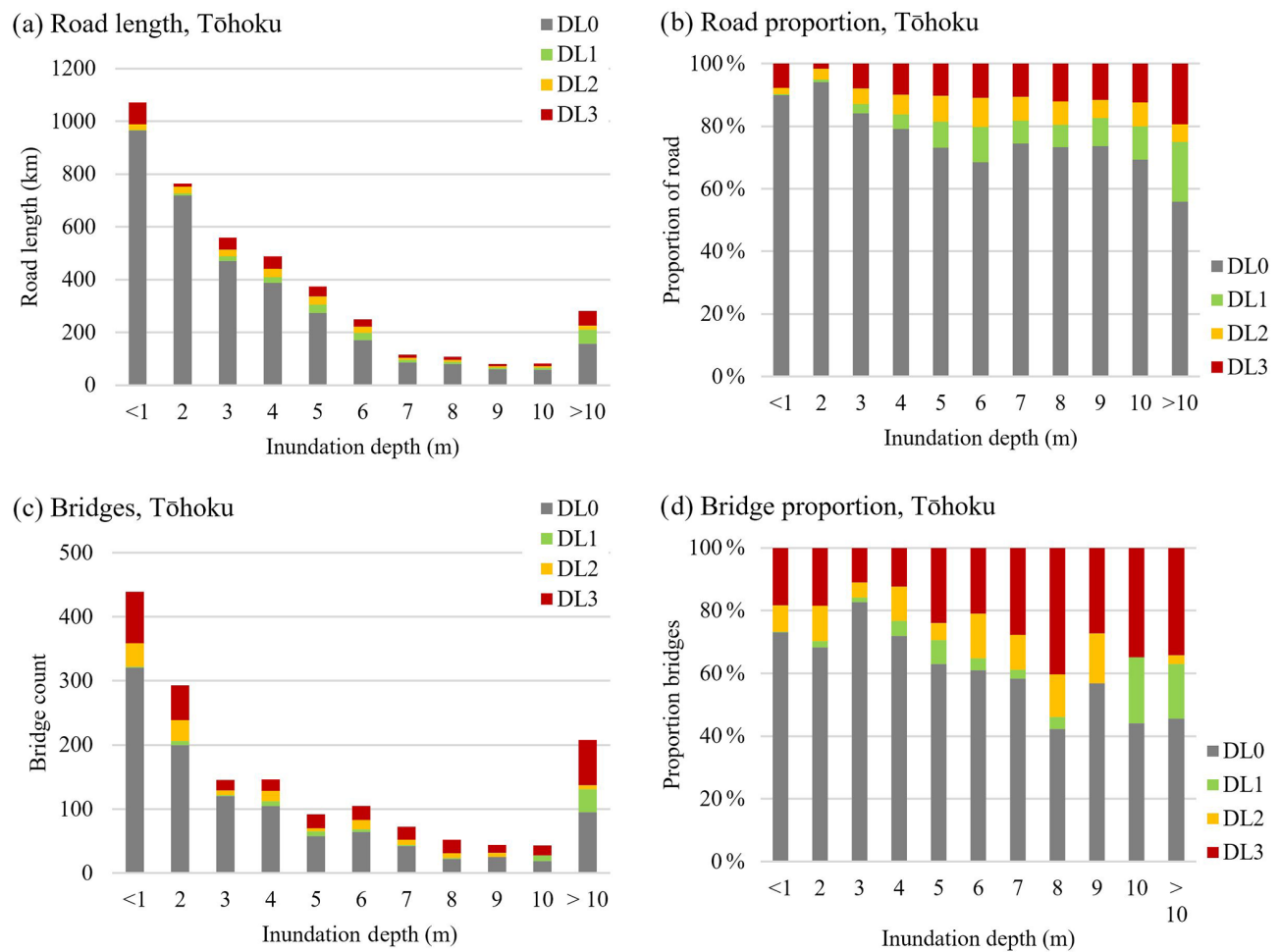

Figure 5. Total length (a) and proportion (b) of exposed roads and number (c) and proportion (d) of exposed bridges, by inundation depth, in Miyagi and Iwate prefectures for the 2011 Tōhoku earthquake and tsunami. 


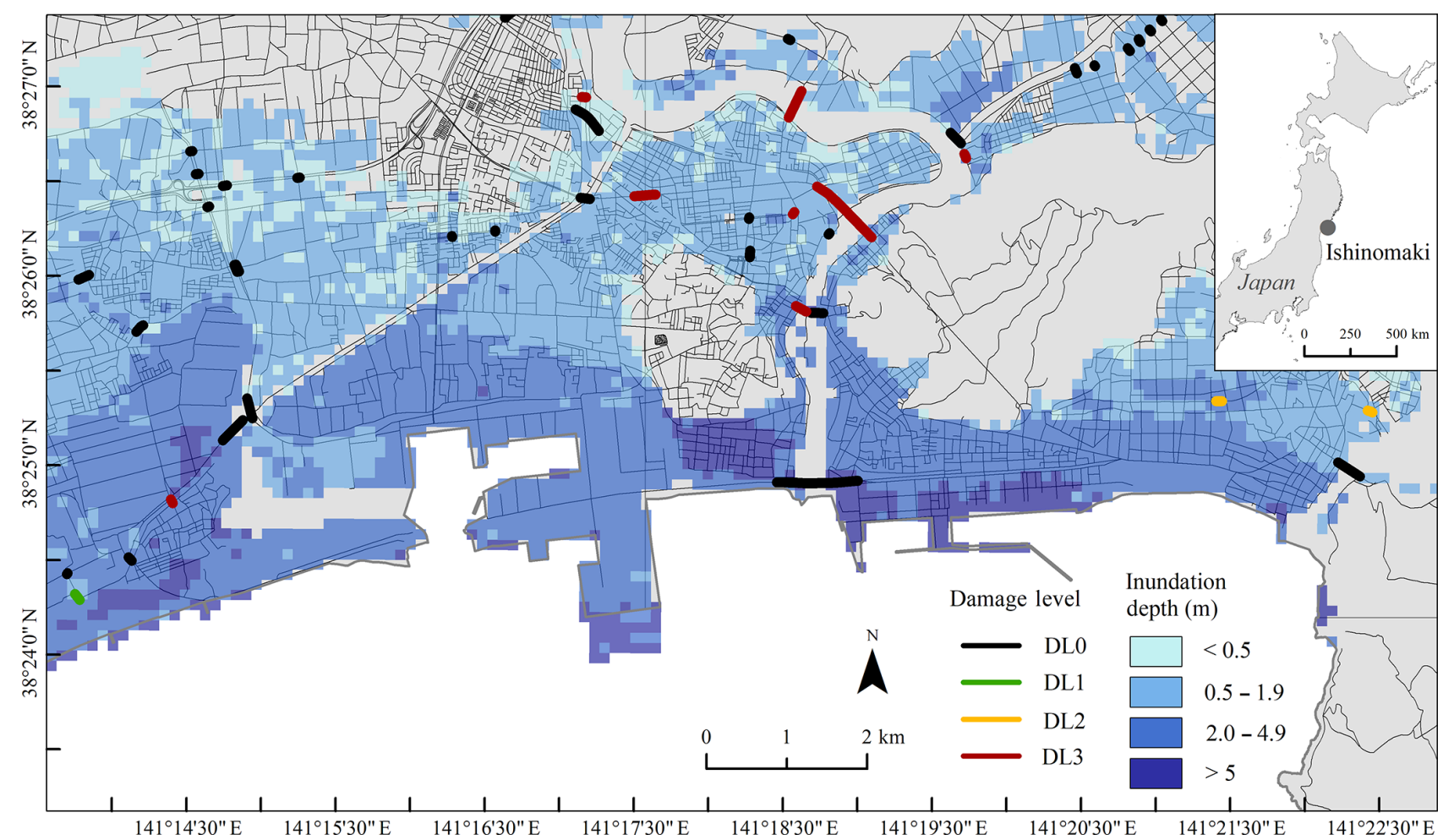

Figure 6. Damage states for inundated bridges in Ishinomaki, Japan, for the 2011 Tōhoku earthquake and tsunami. Bridge impact data modified from MLIT, 2012. (C) OpenStreetMap contributors 2015. Distributed under a Creative Commons BY-SA License.

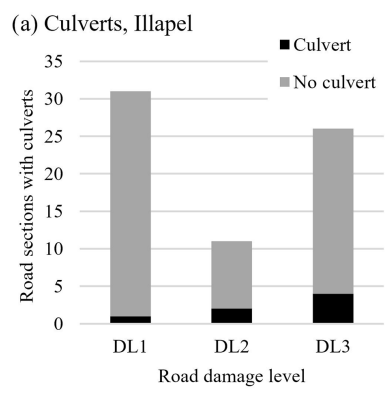

(b) Culvert proportion, Illapel

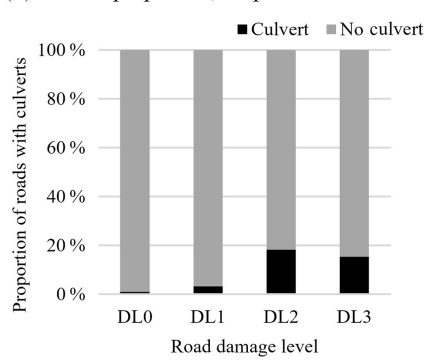

Figure 7. Number (a) and proportion (b) of road sections with or without a culvert, by damage level, for the 2015 Illapel earthquake and tsunami. Note: DL0 had a count of 573 road sections (too many to represent in panel a), with 5 having a culvert.

cations were used to assign the presence of a culvert-outfall pipe (present "1", not present "0") to each $50 \mathrm{~m}$ section of road. The frequency and proportion of road sections with a culvert were tabulated for each damage level (Fig. 7). DL0 had a count of 573 road sections (too many to represent in Fig. 7a), with 5 having a culvert. This analysis is not conducive to fragility functions, due to the limited number of culverts surveyed, so none are developed in this study.

\subsubsection{Distance from coastline}

Tsunami inundation velocity is known to have a considerable influence on asset impacts, especially due to scour. However, inundation velocity data were not available for the Illapel dataset, so distance from the coast was used as a proxy for inundation velocity. This assumes a constant deterioration of landward wave energy including horizontal and vertical buoyancy pressure as a tsunami wave moves inland (from friction and gravity). This was observed for road assets in Coquimbo, as damage levels reduced with distance from the coast. A measure of distance from the coast was calculated at $25 \mathrm{~m}$ inundation distance bins (i.e. $0.0-25.0,25-50 \mathrm{~m}$, etc.). Each road section was assigned the associated distance-fromcoastline value, and the results were tabulated for each damage level as counts and proportions of damage (Fig. 8). Since distance from the coastline is not a direct damage-causing process, the analysis is not conducive to fragility functions, so none are developed for this study.

\subsubsection{Debris-based level of service}

Another consideration of vulnerability is to look at various impact types. As mentioned in Sect. 1, debris can cause considerable disruption to transportation networks through direct damage and through blocking routes. Therefore the effects of debris on an asset's level of service is considered, and 

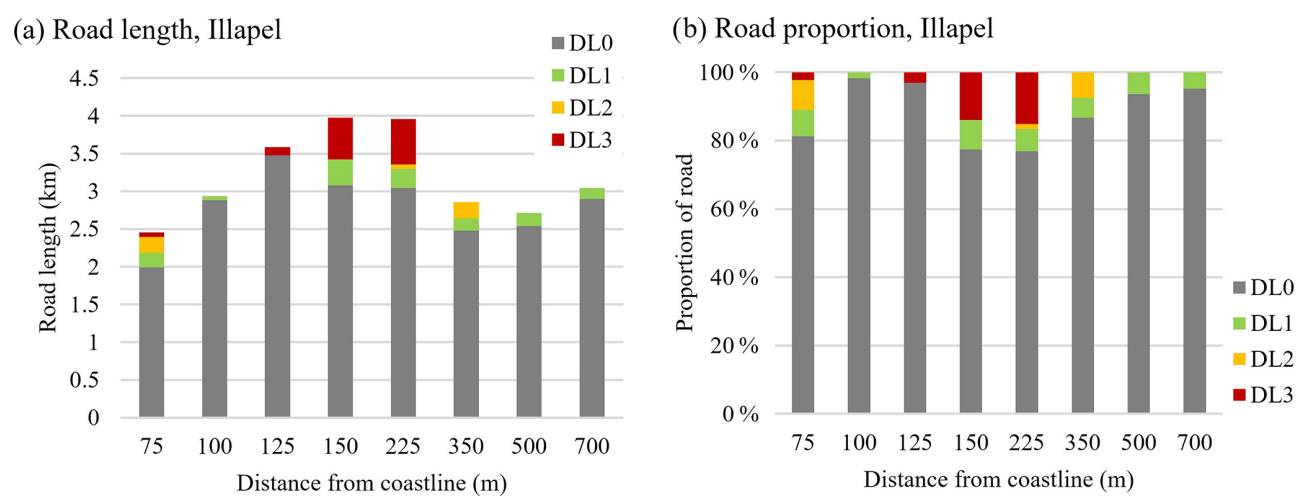

Figure 8. Total length (a) and proportion (b) of exposed roads, by distance from the coastline (as a proxy for inundation energy), for the 2015 Illapel earthquake and tsunami.

a new HIM (distance from the landward inundation extent) is used. To assess the correlation with debris and a road's level of service in Coquimbo, debris distribution data are required. However debris clean-up had begun prior to the survey, so publicly available drone-mounted camera footage (Puerto Creativo, 2015, 2016) was used to map out debris density on roadways. These were classified into five service levels (SLs), as defined in Table 2. SLU represents areas of ponding observed and is classed separately, since the depth and amount of debris entrained is not known. If a road was not associated with debris deposition, it was assigned SLO. To account for potential horizontal sorting of debris, the distance from the tsunami inundation extent (i.e. the greatest recorded landward observations of tsunami inundation) was used and each road was assigned an associated value. The tsunami-exposed area in Coquimbo was predominantly flat topography, with only a few instances of a retaining wall or incline bounding the landward inundation extent. The local sea port, which is typically a well-defined region of debris origin (Naito et al., 2014), was located along the south-westnorth-west inundated coastline.

As well as inundation depth (m) and distance from the coast $(\mathrm{m})$, each road section was now assigned a level of service (SL0-SL3 or SLU; Fig. 9) and a distance from the inundation extent value (in $\mathrm{m}$ ). For each distance measure, road length frequency was tabulated by $25 \mathrm{~m}$ bins (i.e. 0.0 25.0, 25.0-50 m, etc.) for each service level (Fig. 10). There was no such empirical source of debris density observations available for the 2011 Tōhoku tsunami, so this is not considered in the analysis of the Tōhoku dataset.

\subsubsection{Coastal topography}

Fragility functions that do not consider topography may not accurately represent tsunami damage characteristics when used for subsequent impact assessment. Therefore this study defines vulnerability for two broad coastal settings, "coastal plains" and "coastal valleys", to develop specific vulnerability curves similarly to De Risi et al. (2017) and Suppasri et al. (2013). The data for Tōhoku roads, presented above, were further refined by assigning each road section an applicable topographic setting (Fig. 11). For the two different topographic settings, the number and proportion of road sections in each damage level were tabulated against inundation depth (Fig. 12). The resulting fragility functions are presented in Sect. 3 .

\subsection{Developing fragility functions}

The asset damage probabilities for each damage level were calculated and shown against a median value within increasing HIM bins to account for lower amounts of data at a higher HIM. Following the methods of Koshimura et al. (2009) linear regression analysis was performed to develop the log-normal cumulative-distribution-function vulnerability curves. A probability $P$ of reaching or exceeding a damage level for a given hazard intensity value is given by either Eqs. (1) or (2):

$$
\begin{aligned}
& P(x)=\Phi\left[\frac{x-\mu}{\sigma}\right], \\
& P(x)=\Phi\left[\frac{\ln x-\mu^{\prime}}{\sigma^{\prime}}\right],
\end{aligned}
$$

where $\Phi$ is the standardised normal (log-normal) distribution function, $x$ is the HIM (i.e.. inundation depth), and $\mu$ and $\sigma$ $\left(\mu^{\prime}\right.$ and $\left.\sigma^{\prime}\right)$ are the mean and standard deviation of $x(\ln x)$, respectively. Two statistical parameters of fragility function, i.e. $\mu$ and $\sigma\left(\mu^{\prime}\right.$ and $\left.\sigma^{\prime}\right)$, are obtained by plotting $x(\ln x)$ and the inverse of $\Phi^{-1}$ on normal or log-normal plots and performing the least-squares fitting of this plot. Two parameters are obtained by taking the intercept $\left(=\mu\right.$ or $\left.\mu^{\prime}\right)$ and the slope $\left(=\sigma\right.$ or $\left.\sigma^{\prime}\right)$ in either Eqs. (3) or (4), depending on the result of the least-squares fitting:

$$
\begin{aligned}
& x=\sigma \Phi^{-1}+\mu, \\
& \ln x=\sigma^{\prime} \Phi^{-1}+\mu^{\prime} .
\end{aligned}
$$


Table 2. Classification schema for road level of service for the 2015 Illapel earthquake and tsunami. Images taken as screenshots sourced from Puerto Creativo (2015).

\begin{tabular}{llllll}
\hline Service level & U & 0 & 1 & 2 & 3 \\
\hline $\begin{array}{l}\text { Service level } \\
\text { description }\end{array}$ & $\begin{array}{l}\text { Unknown (surface } \\
\text { ponding) }\end{array}$ & $\begin{array}{l}\text { No loss of } \\
\text { service }\end{array}$ & $\begin{array}{l}\text { Vehicle access at a } \\
\text { reduced speed }\end{array}$ & $\begin{array}{l}\text { All-wheel drive vehicle } \\
\text { access at reduced speed }\end{array}$ & No vehicle access \\
\hline Image & & & & &
\end{tabular}

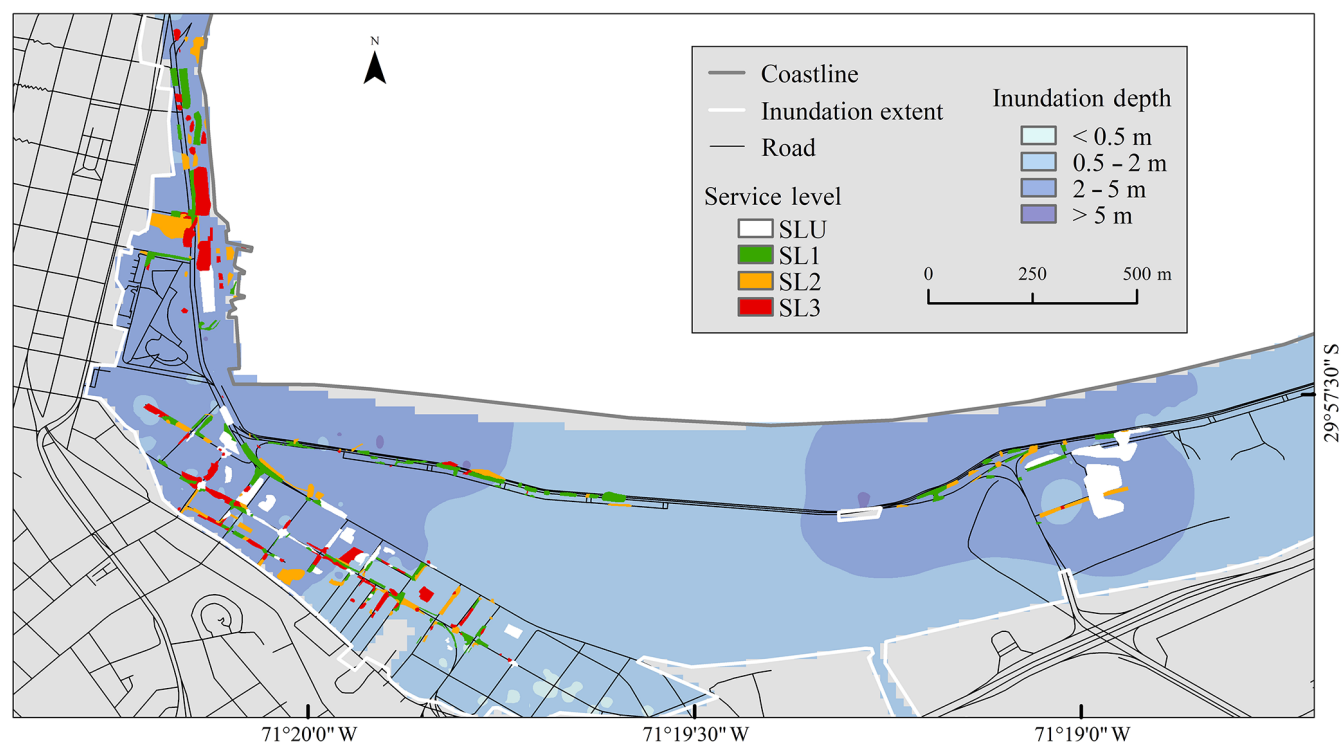

Figure 9. Service levels associated with debris on roads in Coquimbo following the 2015 Illapel earthquake and tsunami, Chile. (C) OpenStreetMap contributors 2015. Distributed under a Creative Commons BY-SA License.

The resulting fragility functions from each dataset are presented in the following section, although not all of the data analysed in this study are applicable to the development of fragility functions.

\section{Results}

Variations in asset impacts are presented, with the developed fragility functions each reflecting a potential difference in damage probability due to (1) damage level only (for each event data), (2) road-use type, (3) distance from coastline (as a proxy for inundation velocity), (4) debris-based level of service, (5) topographic setting, and (6) a consideration of both use type and topographic setting. The results of this study are presented in Table 3 and the following sections.

\subsection{Damage level}

The exposed roads assessed in this study perform well in general, even under the highest inundation depths. There is less than 0.2 and less than 0.3 probability of complete washout (DL3) at $15 \mathrm{~m}$ inundation depth for roads and bridges, respectively, in the Tōhoku dataset (Figs. 13a and 14). Roads in Coquimbo have less than 0.25 probability of complete damage (DL3) at $15 \mathrm{~m}$ (Fig. 13b). By comparison, a reinforced concrete building has a 0.4 probability of reaching or exceeding complete damage at the same inundation depth (Suppasri et al., 2013). All Tōhoku road damage levels are at a lower probability than that of the equivalent Tōhoku bridges. This is to be expected, as each asset has a different tsunami loading regime, with road impacts associated with scour, while bridge impacts are related to horizontal loading 


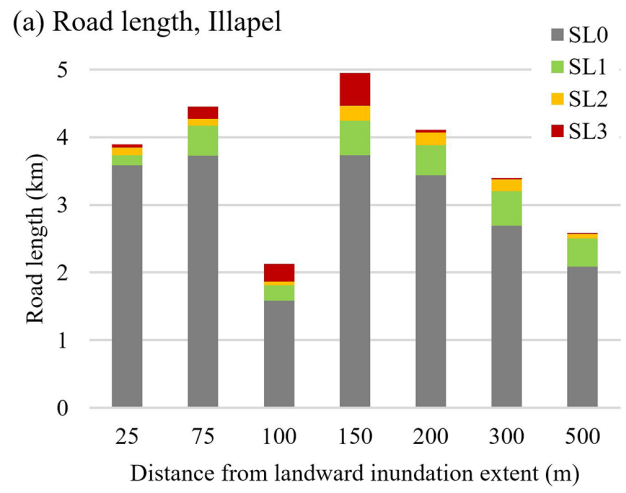

(b) Road proportion, Illapel

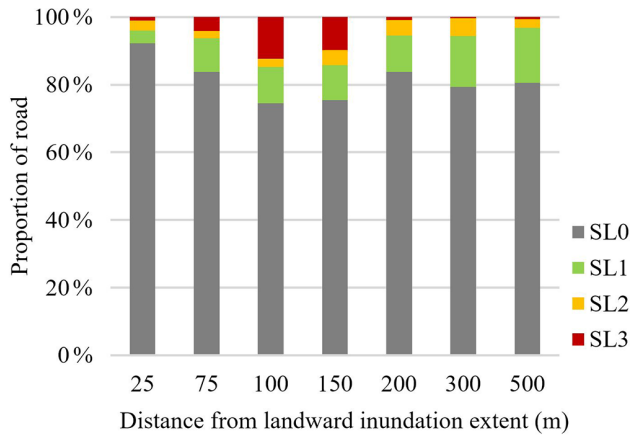

Figure 10. Total length (a) and proportion (b) of exposed roads, considering levels of service, by distance from the landward inundation extent, for the 2015 Illapel earthquake and tsunami. Note that SLU is not considered in analysis.

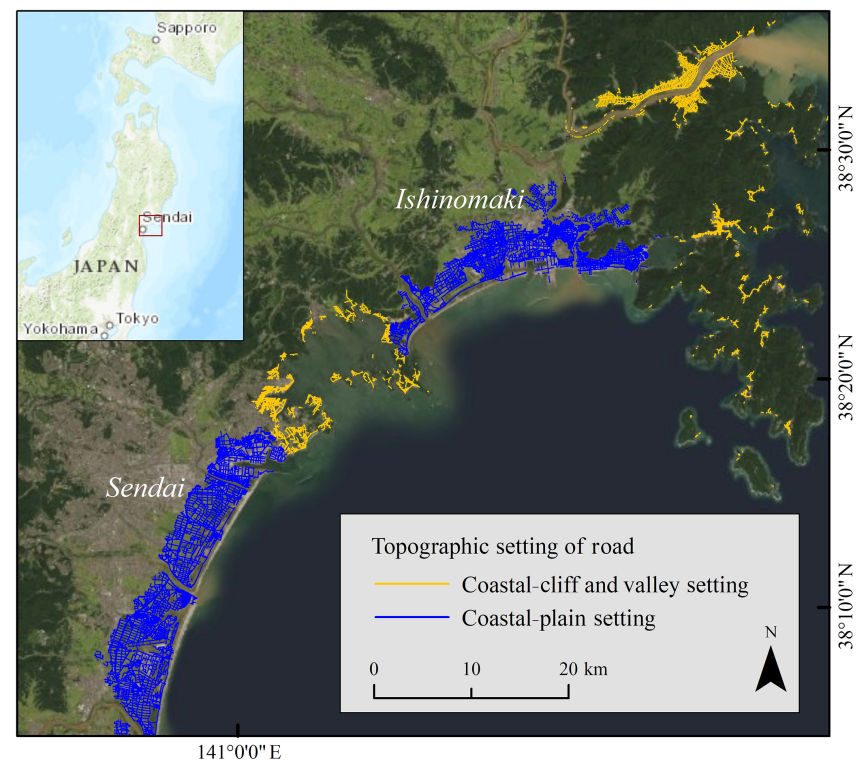

Figure 11. Coastal topographic settings for inundated roads in Miyagi and Iwate prefectures for the 2011 Tōhoku tsunami, Japan. Note: all roads north of Ishinomaki are coastal valleys; all roads south of Sendai are coastal plains. Road data modified from MLIT, 2012, and (C) OpenStreetMap contributors, 2015. Distributed under a Creative Commons BY-SA License. Japan topographic imagery sourced from ESRI contributors (2019a). Tōhoku regional satellite imagery sourced from ESRI contributors (2019b).

across piers and the superstructure as well as vertical loading across the bridge superstructure. Bridges are typically exposed to higher levels of hydrodynamic forces (both horizontal and vertical), as tsunami flows are concentrated in the channels these bridges span. Although not considered in this study, flexible bridge connections will reduce tension from tsunami loadings when compared to rigid (i.e. steel) connections. A higher flexibility in the substructure will also reduce horizontal tsunami loadings (Istrati et al., 2017; Istrati and Buckle, 2014). The Coquimbo roads are at a higher probabil- ity of damage compared with the Tōhoku roads and bridges. This is to be expected given the differing levels of construction standards in Japan in comparison to Chile. The Illapel study area did not contain any roads that could be considered equivalent in capacity to the likes of Japanese state roads, which would be given the highest design standards in terms of maximum flexibility and loading design. This will have resulted in a lower overall vulnerability for mixed-construction Tōhoku roads (Fig. 13a) when compared with the mixedconstruction road vulnerability for Illapel (Fig. 13b). None of the functions have a probability of 1.0 within the parameters of the presented results (i.e. up to $15 \mathrm{~m}$ inundation). This is a reasonable interpretation, as roads and bridges, although particularly vulnerable under certain conditions, are far more resistant to tsunami impacts than many other assets (Williams et al., 2019). As a comparison, mixed-construction buildings in the 2011 Tōhoku earthquake and tsunami had a probability of 1.0 at all damage levels when inundation exceeds $10 \mathrm{~m}$ (Suppasri et al., 2013). Bridge piers and abutments are designed with scour, horizontal loading and vertical loading from moving water in mind, although not specifically for tsunami forces, whereas the foundations and structures of buildings are typically not designed for this purpose, making them more vulnerable to tsunamis.

The results of the analysis on culvert locations and the associated road damage levels in Coquimbo indicate a correlation with the presence of a culvert and an increased damage level (Fig. 15). This indicates that all instances of a culvert in this event have resulted in road damage to some extent and in most cases moderate or severe damage (DL2 and DL3).

\subsection{Distance from coastline}

The analysis for distance from the coast, as a proxy for inundation energy, did not warrant the development of vulnerability curves (Sect. 2.2.2). However, the results (Fig. 16) show a clear trend between higher probabilities of damage occurring closer to the coastline. This may be an indicator for deteriorating wave energy (due to surface friction and gravity) but 
(a) Road length, coastal valleys, Tōhoku

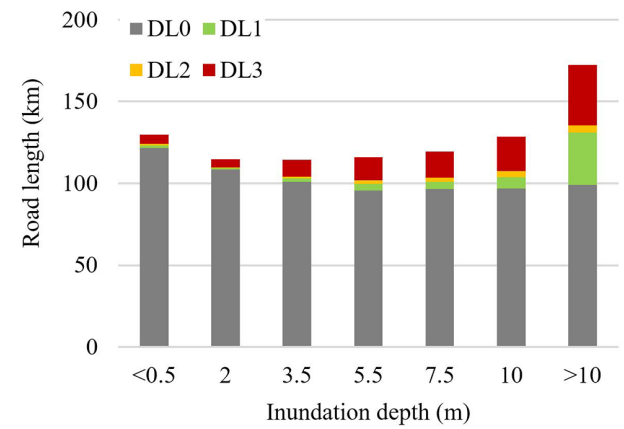

(c) Road length, coastal plains, Tōhoku

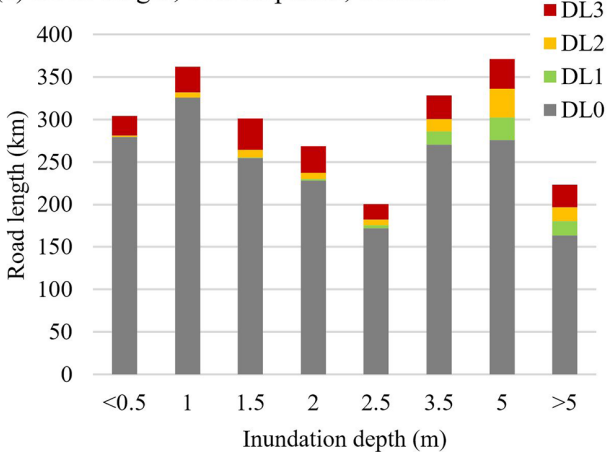

(b) Road proportion, coastal valleys, Tōhoku

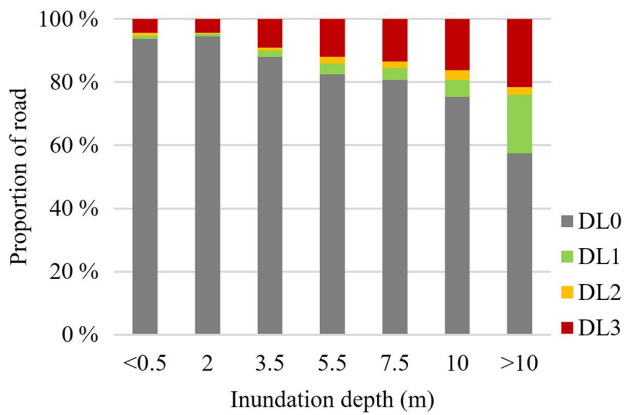

(d) Road proportion, coastal plains, Tōhoku

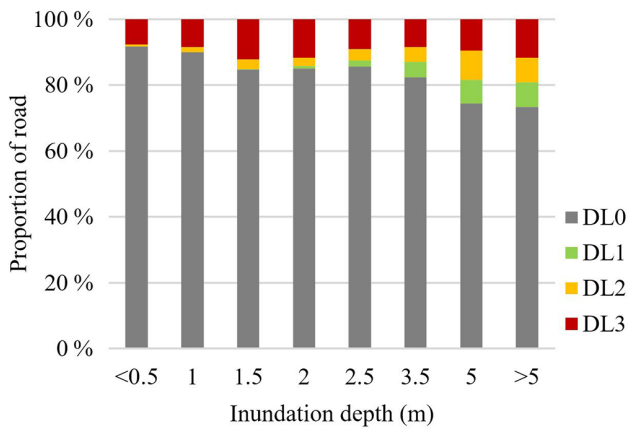

Figure 12. Total length (a) and proportion (b) of exposed roads in a coastal-valley topographic setting and total length (c) and proportion (d) of exposed roads in a coastal-plain topographic setting, by inundation depth, for the 2011 Tōhoku earthquake and tsunami.

(a) Mixed roads, Tohoku

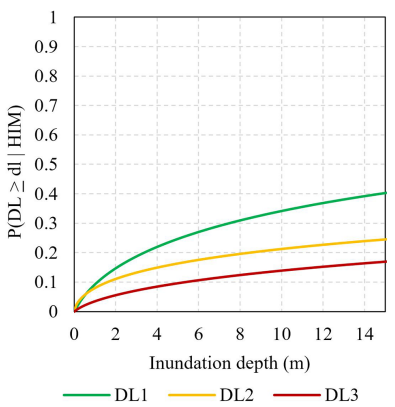

(b) Mixed roads, Illapel

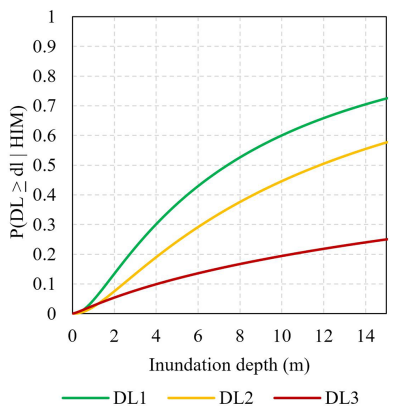

Figure 13. Fragility functions for mixed-construction roads (a) for the 2011 Tōhoku earthquake and tsunami, Japan, and for mixedconstruction roads (b) for the 2015 Illapel earthquake and tsunami, Chile.

could simply be an indicator of increased inundation depths at the coast, since there is no empirical evidence of hydrodynamic forces in the Illapel event. The same was noted in a study of building vulnerability in the Illapel event (Aránguiz et al., 2018), particularly with less damage occurring beyond a wetland area and behind a raised railway ballast, when compared to those nearer the coast.

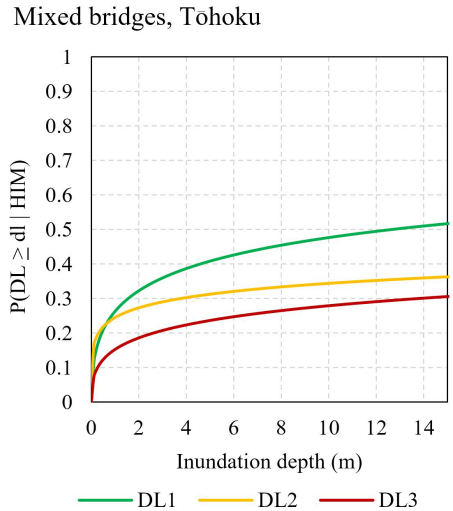

Figure 14. Fragility function for mixed-construction road bridges for the 2011 Tōhoku earthquake and tsunami, Japan.

\subsection{Debris-based level of service}

Tsunami debris transport is a function of inundation depth, inundation velocity and debris size, resulting in horizontal sorting of objects toward the inland inundation extent as larger materials fall out of suspension (Charvet et al., 2014; Evans and McGhie, 2011; Naito et al., 2014; Prasetya et al., 2012). In Coquimbo the debris-based level of service analysis is indicative of this statement, as a higher proportion of 
Table 3. Curve parameters for the tsunami fragility functions developed for transportation assets*.

\begin{tabular}{|c|c|c|c|}
\hline Fragility function & $\mu$ & $\sigma$ & $r^{2}$ \\
\hline Tōhoku ID MX roads: DL1 & 3.33 & 2.51 & 0.83 \\
\hline Tōhoku ID MX roads: DL2 & 5.31 & 3.77 & 0.82 \\
\hline Tōhoku ID MX roads: DL3 & 5.76 & 3.18 & 0.80 \\
\hline Tōhoku ID MX bridges: DL1 & 2.53 & 4.01 & 0.84 \\
\hline Tōhoku ID MX bridges: DL2 & 5.52 & 8.00 & 0.55 \\
\hline Tōhoku ID MX bridges: DL3 & 5.38 & 5.25 & 0.60 \\
\hline Illapel DC MX roads: DL1 & 0.16 & 0.00 & 0.34 \\
\hline Illapel DC MX roads: DL2 & 0.10 & 0.00 & 0.36 \\
\hline Illapel DC MX roads: DL3 & 0.07 & 0.00 & 0.31 \\
\hline Illapel ID MX roads: DL1 & 2.00 & 1.18 & 0.82 \\
\hline Illapel ID MX roads: DL2 & 2.47 & 1.23 & 0.71 \\
\hline Illapel ID MX roads: DL3 & 4.16 & 2.16 & 0.48 \\
\hline Tōhoku ID SR road: DL1 & 3.68 & 1.64 & 0.82 \\
\hline Tōhoku ID SR road: DL2 & 5.35 & 2.58 & 0.67 \\
\hline Tōhoku ID SR road: DL3 & 6.04 & 2.77 & 0.52 \\
\hline Tōhoku ID LR road: DL1 & 2.28 & 2.58 & 0.75 \\
\hline Tōhoku ID LR road: DL2 & 3.21 & 4.06 & 0.65 \\
\hline Tōhoku ID LR road: DL3 & 9.33 & 10.03 & 0.52 \\
\hline Tōhoku ID PR road: DL1 & 2.22 & 2.68 & 0.75 \\
\hline Tōhoku ID PR road: DL2 & 4.29 & 4.65 & 0.73 \\
\hline Tōhoku ID PR road: DL3 & 4.77 & 3.29 & 0.53 \\
\hline Tōhoku ID MR road: DL1 & 1.73 & 1.31 & 0.92 \\
\hline Tōhoku ID MR road: DL2 & 2.23 & 1.75 & 0.90 \\
\hline Tōhoku ID MR road: DL3 & 2.50 & 1.80 & 0.83 \\
\hline Tōhoku ID UR road: DL3 & 0.83 & 4.99 & 0.76 \\
\hline Tōhoku CP ID MX roads: DL1 & 4.88 & 4.07 & 0.90 \\
\hline Tōhoku CP ID MX roads: DL2 & 8.25 & 6.74 & 0.87 \\
\hline Tōhoku CP ID MX roads: DL3 & 17.01 & 12.42 & 0.73 \\
\hline Tōhoku CV ID MX roads: DL1 & 3.40 & 1.75 & 0.94 \\
\hline Tōhoku CV ID MX roads: DL2 & 5.07 & 3.02 & 0.93 \\
\hline Tōhoku CV ID MX roads: DL3 & 5.42 & 3.11 & 0.95 \\
\hline Tōhoku ID CP SR road: DL1 & 5.21 & 2.71 & 0.95 \\
\hline Tōhoku ID CP SR road: DL2 & 5.15 & 2.58 & 0.90 \\
\hline Tōhoku ID CP SR road: DL3 & 4.64 & 2.04 & 0.95 \\
\hline Tōhoku ID CV SR road: DL1 & 3.03 & 1.11 & 0.58 \\
\hline Tōhoku ID CV SR road: DL2 & 3.29 & 0.75 & 0.56 \\
\hline Tōhoku ID CV SR road: DL3 & 3.33 & 0.63 & 0.58 \\
\hline Tōhoku ID CP LR road: DL1 & 3.35 & 4.07 & 0.80 \\
\hline Tōhoku ID CP LR road: DL2 & 3.49 & 4.17 & 0.81 \\
\hline Tōhoku ID CP LR road: DL3 & 6.95 & 7.30 & 0.67 \\
\hline Tōhoku ID CV LR road: DL1 & 1.33 & 3.43 & 0.56 \\
\hline Tōhoku ID CV LR road: DL2 & 3.30 & 6.99 & 0.44 \\
\hline Tōhoku ID CV LR road: DL3 & 16.31 & 16.31 & 0.339 \\
\hline
\end{tabular}

* MX is mixed construction, ID is inundation depth as the HIM, DC is distance from coastline as a HIM proxy, CP is coastal-plain topography, CV is coastal-valley topography, $\mathrm{SR}$ is state road, $\mathrm{LR}$ is main local road, $\mathrm{PR}$ is general prefectural road, MR is municipality road, UR is lowest-class roads (unsealed) and $r^{2}$ is regression score.

roads have debris deposited on them between 0 and $150 \mathrm{~m}$ from the landward extent of tsunami inundation $(0 \%-22 \%$ of maximum inland inundation extent). This indicates that

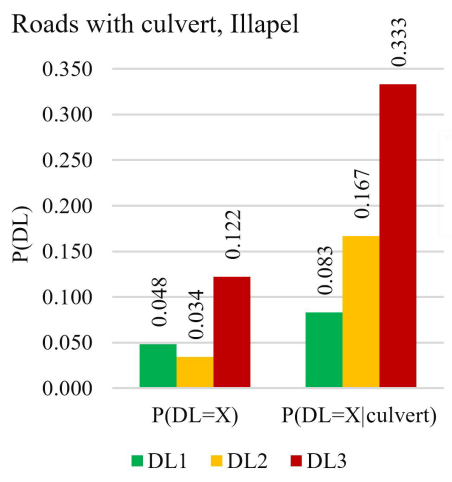

Figure 15. Total road damage probability and increased total road damage probability with the presence of a culvert.

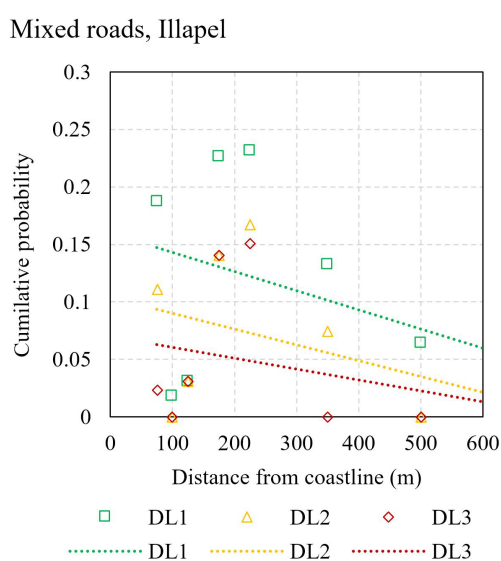

Figure 16. Linear best-fit probability of reaching or exceeding a given damage level, by distance from coastline (as a proxy for inundation energy), for the 2015 Illapel tsunami, Coquimbo, Chile.

debris carried inland falls out of horizontal suspension prior to reaching the maximum inland extent. The results from the debris density analysis show that there is higher debris density between approximately 75.0 and $150.0 \mathrm{~m}(11 \%$ and $22 \%$ ) from the inland inundation extent (Fig. 17). Debris density probability is consistently lower, for all levels of service, between 0.0 and $75.0 \mathrm{~m}(0 \%$ and $11 \%)$ from the inland inundation extent and 200.0 and $672 \mathrm{~m}(30 \%$ and $100 \%)$ from the inland inundation extent. SL1 has a much higher probability of occurrence than SL2 and SL3 at distances $>200 \mathrm{~m}$ from the inland inundation extent (Fig. 17). This is consistent with previous studies and field observations where debris is consistently distributed across an inundation area during landward and seaward inundations.

\subsection{Road-use type}

Using the mixed-construction road data for exposed areas of the Tōhoku event, the different structural types are split into broader use categories, as the closest approximation of construction material, type and method, for the development of 


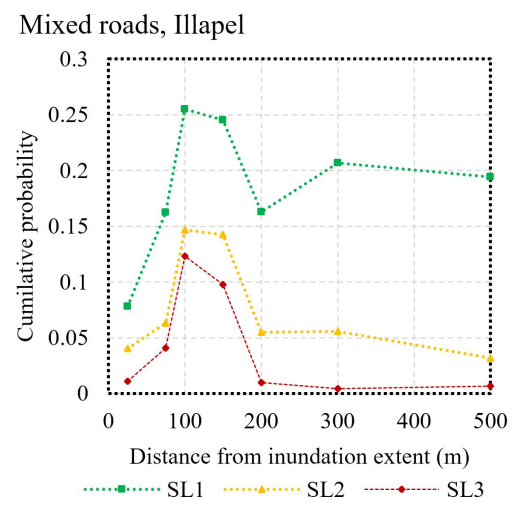

Figure 17. Cumulative probability plot of road service levels compared with a distance from the inland extent of tsunami inundation (as an indication of debris density sorting) for the 2015 Illapel tsunami, Coquimbo, Chile.

fragility functions (Fig. 18). The most resistant use category, with respect to tsunami impacts, is state roads (Fig. 18a), with all damage levels being of a lower probability than the other use categories. This is followed by main local roads and general prefectural roads (Fig. 18b and c), each with very similar probabilities of DL1 and DL3, although main local roads have a higher probability of reaching or exceeding DL3 at less than $7 \mathrm{~m}$ inundation depth. Main local roads (Fig. 18b) also have a higher probability of reaching or exceeding DL2 in comparison to general prefectural roads (Fig. 18c). This can be interpreted as main local roads having a certain characteristic that pushes them from DL1 to DL2 much faster than with general prefectural roads. It is likely these two classes share similar construction standards and materials. Municipality roads (Fig. 18d) have considerably higher probabilities of reaching or exceeding each DL, with a much steeper gradient when compared to road class 1, 2 and 3 (Fig. 18a, b and c). The most vulnerable roads are the lowestclass roads (Fig. 18e), which we cautiously assume here to be unsealed based on pre-event satellite imagery. Given that these roads are scarce in the mostly urban environment of the study area and the unknown nature of their construction, the data for this road class were not sufficient to classify DL1 and DL2. At $3 \mathrm{~m}$ of inundation depth, this road class already exceeds a probability of 0.5 of complete damage (DL3).

\subsection{Coastal topographic setting}

The previous fragility functions for the Tōhoku event, presented above, represent an average of the data for the whole of the tsunami-exposed area. This section presents the results of the analysis looking at the effects of two different topographic settings on tsunami damage to roads. An example of the difference in these coastal topographic settings is that at $2 \mathrm{~m}$ of inundation depth there is $\sim 0.09$ probability of DL3 on plains, whereas this is only $\sim 0.05$ in valleys (Fig. 19a and b). The damage probability in plains increases to $\sim 0.11$ at $10 \mathrm{~m}$ inundation depth, while the damage probability is $\sim 0.16$ for valleys. It is noted that the damage probability for the plains abruptly increases from 0 to 0.08 (at around $0.03 \mathrm{~m}$ ), while for valleys 0.08 is not reached until $3 \mathrm{~m}$.

Since it was already established in Sects. 1 and 2, road-use type (as an estimation of construction type and material) is an important factor in defining tsunami vulnerability. Therefore, the Tōhoku data are again split into different road classes to compare, in more detail, the effects of coastal topography on tsunami vulnerability. Two examples are presented below, for state roads and main local roads (Fig. 20). Road classes 3-5 are not presented here, as these did not have sufficient data to warrant fragility functions. In general, the damage probabilities for roads in the valleys are higher than those on plains for each inundation depth. However, the $r^{2}$ values for coastal valleys are particularly low, so the comparisons between each coastal setting may not be entirely representative of true vulnerability.

\section{Discussion}

This study represents the first attempt at developing empirical tsunami fragility functions for roads. Although previous studies have developed fragility functions for tsunami impacts on road bridges using the Tōhoku dataset (Eguchi et al., 2013), they do not include undamaged assets in the analysis. This is a considerable drawback given that the number of undamaged assets is equally important in developing cumulative distribution functions for damage probability. The fragility functions presented in this study, particularly those based on Tōhoku data, have a number of potential applications within a broader risk reduction framework, particularly in developed countries with similar construction standards to Japan. These can be used in impact and loss forecasting to provide high-resolution estimates (i.e. considering topographic setting and construction material or type) or for more rapid loss modelling if implementing mixed-construction and topographic setting curves. The number of refined curves presented in this study provides flexibility for future global applications. Applications in countries that do not share similar construction standards to Japan or Chile are still possible, ensuring a full understanding of the limitations; for example, a country with different levels of construction standards may have a number of exposed roads that share similar construction standards to a class 4 Japanese road.

This study represents the first empirical analysis directly linking the presence of a road culvert with increased probability of road damage. Although this analysis did not warrant the development of fragility functions, given an applicable case study and consideration of the limitations, these results could be used for weighted tsunami impact assessment. The evidence from this study certainly indicates a need for the consideration and development of mitigation strategies to re- 
(a) State roads, Tōhoku

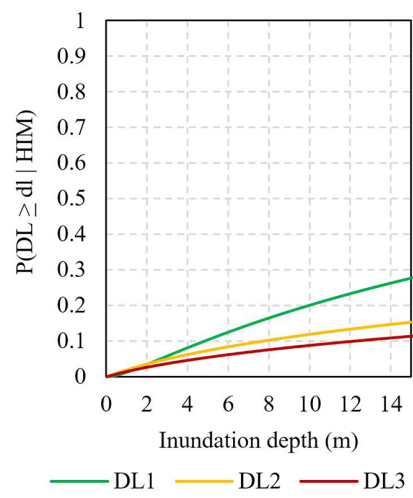

(b) Main local roads, Tōhoku

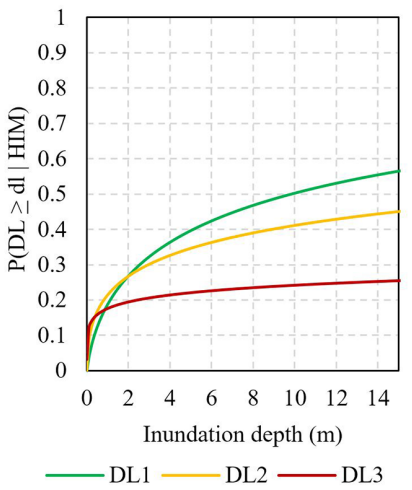

(c) General prefectural roads, Tōhoku

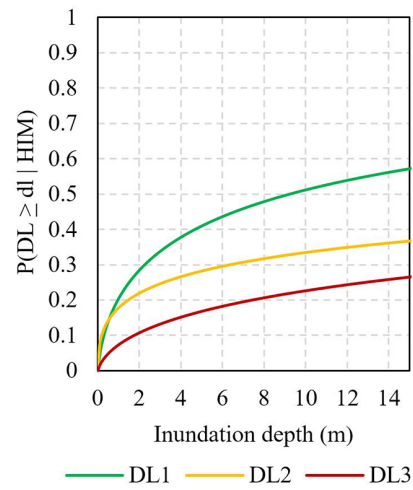

(d) Municipality roads, Tōhoku

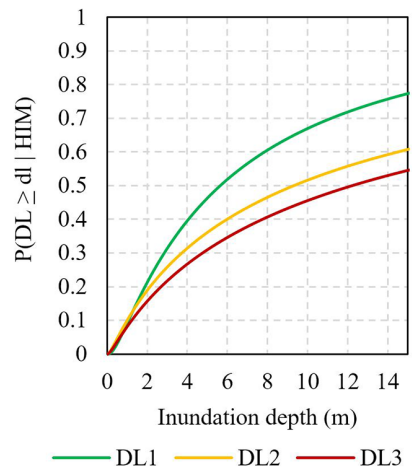

(e) Lowest-class roads, Tōhoku

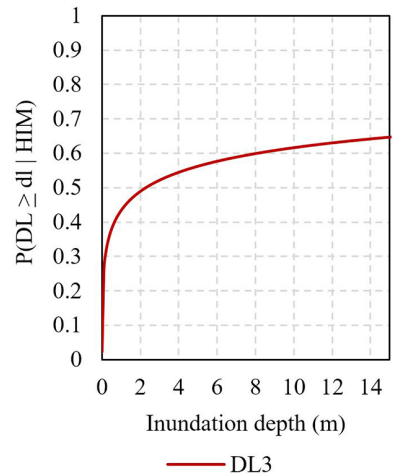

Figure 18. Fragility functions for inundated state roads (a), main local roads (b), general prefectural roads (c), municipality roads (d) and lowest-class roads (e) (as an indicator of construction type and materials) in Miyagi and Iwate prefectures following the 2011 Tōhoku earthquake and tsunami, Japan.

(a) Mixed roads, coastal plains, Tōhoku

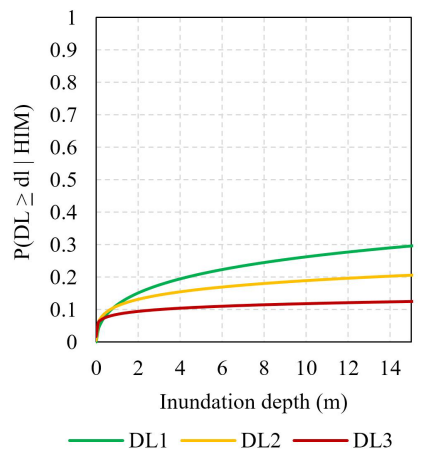

(b) Mixed road type, coastal valleys, Tōhoku

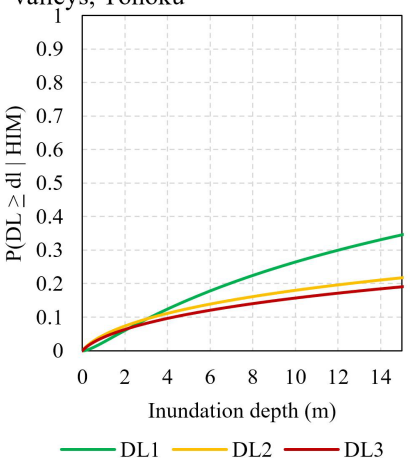

Figure 19. Fragility functions for roads on coastal plains (a) and coastal valleys (b) for the 2011 Tōhoku earthquake and tsunami, Japan.

duce the associated vulnerability of transportation assets located adjacent to culverts exposed to tsunamis.

The analysis of debris deposition density in Coquimbo, and the associated level of service to roads, is also the first of its kind. As with culvert damage, this dataset did not warrant the development of fragility functions; however under the right conditions it could be applied to a weighted vulnerability metric within a wider tsunami impact assessment of road infrastructure. The analysis methods can also be applied to future events.

This study highlights that the collection of post-event tsunami impact data is invaluable for vulnerability analysis of infrastructure assets, which have been under-represented in past studies. The methods used for data collection in this study show that a combination of empirical field survey data and post-survey remote sensing could be an effective way to supplement and refine field observations. In the case of Illapel, the survey was conducted using only a measuring tape and observations recorded on a tablet. This demonstrates that relatively simple survey techniques and equipment can be used to provide rapid "in-and-out" surveys after events of this magnitude in order to collect data on assets that would otherwise not be included by other survey teams. 

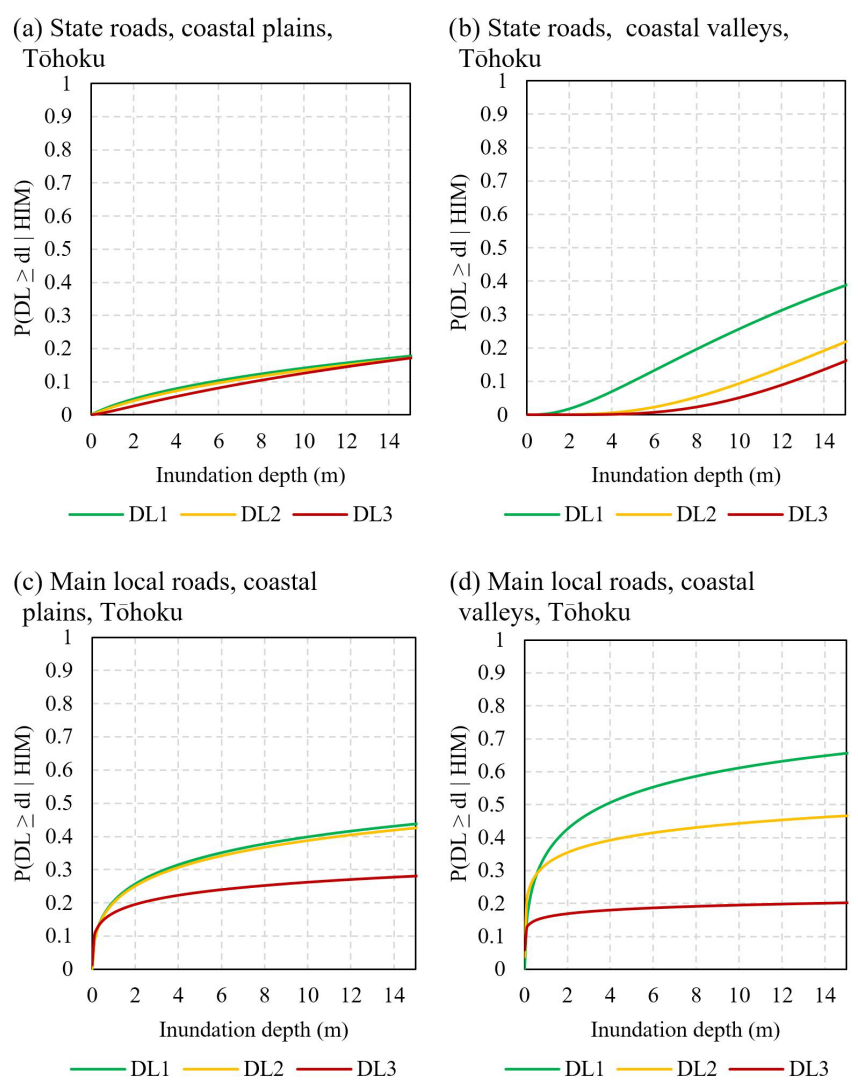

(d) Main local roads, coastal

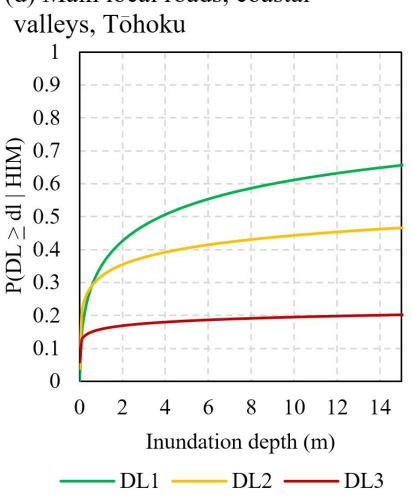

Figure 20. Fragility functions for road state roads on coastal plains (a) and coastal valleys (b) and for main local roads on coastal plains (c) and coastal valleys (d) for the 2011 Tōhoku earthquake and tsunami, Japan.

\subsection{Limitations}

The Illapel data are from a relatively small tsunami event in a localised area of one single coastline. This represents a small sample size but a high level of detail applied though a census-style survey. The Tōhoku data are from a considerably larger sample size, but asset characteristics provided to the authors of this study are in some cases recorded at a low resolution (e.g. the lack of recorded construction material). The quantity of data is important when developing vulnerability curves for a dataset of the Tōhoku scale. For example, fragility functions for road class $3-5$ on the two coastal topographies would not have been applicably comparable to that of class 1 and 2 roads due to the different quantities of data and particularly at higher inundation depths. However the more localised data of Illapel have more consistent quantities of data across the range of inundation depths but are also limited by the overall data size. For example, the dataset did not warrant the comparison of different coastal settings, since only flat topography was represented in the study area, which is also noted by Aránguiz et al. (2018) in the context of building vulnerability. The Tōhoku survey also did not include undamaged (DL0) roads, which, as outlined in
Sect. 2, were remotely sensed through this study on the assumption that any roads not included in the data were DL0. This assumption depends on a range of factors, including scope of survey, access, classification criteria and the accuracy of shapefiles used to classify DL0. DL0 is more likely over-represented in this study than under-represented.

The Tōhoku data represent not only the effects of tsunami hazards but also those from seismically induced shaking, including soil instability. Although in most cases the observed damage will be characteristic of tsunami impacts, some assets may have been initially weakened by seismically induced hazards, including shaking, liquefaction, landslides, lateral spreading and differential settlement. This can be interpreted as the fragility functions potentially overestimating the actual vulnerability of Japanese transportation assets to tsunamis.

As with any field survey data, there is inherent bias in each individual surveyor's assignment of damage levels. With respect to the Illapel data collection this was controlled to some extent by using one consistent survey team member for each asset recorded. It is more difficult to evaluate the Tōhoku dataset in this regard, but it is reasonable to assume that the MLIT survey team grappled with and attempted to mitigate similar issues. However, it is reasonable to note that a subjective bias is possible with both datasets, particularly when comparing with equivalent damage classifications in other tsunami events. The methods used to spatially define the Tōhoku dataset (i.e. $50 \mathrm{~m}$ sections of road) are not as applicable with smaller datasets, such as with the Illapel event. Since some of the DL3 road washouts were smaller than $50 \mathrm{~m}$ in Coquimbo, there is potentially an over-representation of this damage level and potentially even DL1 and DL2. This means that the Illapel curves may be an over-estimation in terms of damage. In addition, some of the worst-damaged roads had already begun repair works and may have been over-represented in the survey.

The results of this study are also limited, to a certain extent, by the methodology used to fit the impact data to fragility curves. Some curves overlap at the lower hazard intensities (e.g. Fig. 14), since the data are treated nominally when fitting curves. This could be addressed by adopting a cumulative link model which fits raw asset impact and hazard intensity data to fragility curves simultaneously (Lallemant et al., 2015).

Information on Japanese culvert locations was not available to the authors of this study. It would have been useful to validate the positive relationship between culverts and road damage in a tsunami against that identified in the Coquimbo case study. We note this may be a fruitful future study. The results for increased road vulnerability associated with the presence of a culvert may be under-represented. The field survey was thorough in its collection of data; however, if culverts and outfall pipes were covered with debris or sediment, they would not have been recorded. Similarly, regarding the classifications for levels of service for debris-affected roads 
in Coquimbo, the drone footage used covered approximately $90 \%$ of the inundation zone. Therefore, some areas may be under-represented for debris deposition as a result.

Another limitation of using another team's survey data is the assumptions made around asset classifications. In the road-use-type fragility functions, road class 1 shows very low vulnerability to inundation depth. This would include Japan's most highly engineered road assets, implying higher construction standards compared with other road-use classes. Road classes 2, 3 and 4 trend very similarly and likely share a similar spread of road construction standards. These also show considerably lower vulnerability to inundation depth than that of class 5 roads. Class 5 roads show high vulnerability at even low inundation depths. This class likely includes roads highly susceptible to erosion. This suggests that at the resolution of this road classification method, there is potentially only a need for three broader classes - highly engineered, standard and low-grade. However ideally the various range of road types considered in this range of data would be separated, which is outside the scope of the present research. The subtleties of use-type classification vulnerability may be a function of geophysical setting of each road class, which could not be tested due to a lack of available high-resolution soil data.

\subsection{Future research}

This study presents a full analysis of empirical post-event tsunami impact data from field survey to refined fragility functions. It can therefore be used as a framework for similar analysis of transportation impact data from future tsunami events. Data from future tsunamis may also provide some degree of refinement to the results presented in this study. Future work should also consider the data collection and analysis of a range of other critical infrastructure assets, such as electricity, telecommunications, water and fuel. There is a considerable knowledge gap on tsunami impacts on infrastructure, which should be better addressed to inform risk reduction strategies.

The Tōhoku dataset of tsunami-damaged roads remains the most extensive in the world, and the vulnerability curves developed from them in this study could be even further refined through more complete data. One particular limitation addressed above is the high concentration of co-seismic hazards the roads were exposed to prior to tsunami inundation. It would be possible to eliminate some assets which were likely earthquake-damaged by using high-resolution geomorphic, soil and liquefaction hazard data from 2011, which were not available to the authors of this study. Given the results of the culvert analysis, future post-event survey data can be used to corroborate the increased vulnerability of roads associated with culverts. This can also be used to inform potential mitigation strategies to increase the resilience of roads and culverts alike. This could also be done for the Tōhoku dataset if pre-event surface drainage channel data (i.e. an indicator of culverts location) were used, which were not available to the authors of this study. Similarly, the Tōhoku dataset could be further refined by eliminating potentially undamaged roads (those covered in debris during the survey but not physically damaged). Aerial or satellite imagery could be used for this or using the observations from the Illapel debris analysis (Fig. 17) in this study to apply a proportional alteration to the dataset (e.g. removing an equivalent proportion of roads within $11 \%-22 \%$ of the inundation extent).

Future post-event tsunami surveys should include data on debris dispersal and deposition if possible. It is acknowledged that a lack of time and resources often plays a defining role in the type and quantity of data collected by survey teams, but if technology such as high-definition (HD) drone footage or rapid $\mathrm{HD}$ aerial photography were conducted after tsunami events, this could be combined with ground-level observations on debris. This is often not possible, as communities begin cleaning debris almost immediately after an event. In the case of Coquimbo, all roads were cleared of debris by the field team's arrival, $6 \mathrm{~d}$ after the event.

During the analysis, several interesting damage characteristics were potentially identified, although there were not enough data to develop robust fragility functions, particularly as the small sample size at Coquimbo reduces the ability to derive a robust statistical sample. Therefore, the observation remains qualitative and the parameters require further investigation from future events. One such observation is the potentially increased chance of road damage in Coquimbo given the presence of a culvert $(91 \%$ roads with culverts $\geq$ DL2). Future post-event tsunami surveys should consider the collection of data for these types of observations to validate against those presented in this study.

\section{Conclusions}

Data from two comparable tsunamis are used to develop fragility functions for roads and bridges. The results of this analysis conclude the following.

- Roads with higher construction standards perform better during tsunamis than those with lower standards. This is evident in use types (based on design parameters based on capacity), showing that the higher-capacity roads have lower tsunami vulnerability.

- Bridges are more vulnerable to the impacts of tsunamis than roads. However, a more appropriate direct comparison is between buildings and bridges; bridges are better designed to withstand the forces of tsunami loading and have a lower level of vulnerability at all hazard intensities (inundation depth) compared with buildings.

- Field survey observations can be effectively supplemented with remotely sensed data to compare various HIMs with subtleties in asset attributes to define tsunami vulnerability, including the following: 
- Roads in coastal valleys are more vulnerable than those on coastal plains; however "state roads" on coastal plains have higher vulnerability at low inundation depths, compared to coastal valleys, which is then exceeded at higher inundation depths in coastal valleys, when compared to coastal plains.

- Culverts represent particularly vulnerable sections of roads due to the effects of contraction forces on the associated subgrade they are embedded through.

- Debris are horizontally sorted across areas of tsunami inundation, with the highest densities of deposition found within 75 and $150 \mathrm{~m}(11 \%-22 \%)$ from the inland extent of inundation (in the case of the Illapel event). Greater densities of debris on a road decrease its level of service.

The suite of tsunami fragility functions for transportation assets presented in this study address a considerable gap in global knowledge. These functions can be applied through tsunami impact assessments to inform tsunami risk reduction strategies. Future tsunami impact surveys should collect more data, especially on infrastructure asset attributes, at higher spatial resolutions, and rapid post-event data capture is critical to the development of robust fragility functions.

Data availability. The Illapel dataset is available at: https://doi.org/10.6084/m9.figshare.11839323.v1 (Williams, 2020). The Tōhoku dataset is available from MLIT (MLIT, 2012).

Author contributions. JHW, NH and RP conducted fieldwork. All authors contributed to the paper preparation (JHW, TMW, NH, RP, LW, EML and MWH).

Competing interests. The authors declare that they have no conflict of interest.

Special issue statement. This article is part of the special issue "Natural hazard impacts on technological systems and infrastructures". It is a result of the EGU General Assembly 2018, Vienna, Austria, 8-13 April 2018.

Acknowledgements. The authors would like to acknowledge the Ministry of Land Infrastructure Transport and Tourism (MLIT) for the provision of field-survey data as well as funding contributions from GNS Science, the Earthquake Commission Capability Fund to the Department of Geological Sciences, University of Canterbury, the University of Auckland, the Mason Trust Fund, Environment Canterbury, and the Christchurch City Council.
Financial support. This research has been supported by NIWA Taihoro Nukurangi (grant no. CARH2006) and the Resilience to Nature's Challenges (MBIE) Resilience Rural Backbone programme (grant no. GNS-Resilience003).

Review statement. This paper was edited by Elena Petrova and reviewed by Grant Wilson and Constance Ting Chua.

\section{References}

Aránguiz, R., González, G., González, J., Catalán, P. A., Cienfuegos, R., Yagi, Y., Okuwaki, R., Urra, L., Contreras, K., Del Rio, I., and Rojas, C.: The 16 September 2015 Chile Tsunami from the Post-Tsunami Survey and Numerical Modeling Perspectives, Pure Appl. Geophys., 173, 333-348, https://doi.org/10.1007/s00024-015-1225-4, 2016.

Aránguiz, R., Urra, L., Okuwaki, R., and Yagi, Y.: Development and application of a tsunami fragility curve of the 2015 tsunami in Coquimbo, Chile, Nat. Hazards Earth Syst. Sci., 18, 2143-2160, https://doi.org/10.5194/nhess-18-2143-2018, 2018.

Ballantyne, D.: Sri Lanka lifelines after the December 2004 Great Sumatra earthquake and tsunami (SUPPL. 3), Earthq. Spectra, 22, 545-559, https://doi.org/10.1193/1.2211367, 2006.

Bojorquez, E., Iervolino, I., Reyes-Salazar, A., and Ruiz, S. E.: Comparing vector-valued intensity measures for fragility analysis of steel frames in the case of narrow-band ground motions, Eng. Struct., 45, 472-480, https://doi.org/10.1016/j.engstruct.2012.07.002, 2012.

Charvet, I., Suppasri, A., and Imamura, F.: Empirical fragility analysis of building damage caused by the 2011 Great East Japan tsunami in Ishinomaki city using ordinal regression, and influence of key geographical features, Stoch. Env. Res. Risk A., 28, 1853-1867, https://doi.org/10.1007/s00477-014-0850-2, 2014.

Contreras-López, M., Winckler, P., Sepúlveda, I., Andaur-Álvarez, A., Cortés-Molina, F., Guerrero, C. J., Mizobe, C. E., Igualt, F., Breuer, W., Beyá, J. F., Vergara, H., and Figueroa-Sterquel, R.: Field Survey of the 2015 Chile Tsunami with Emphasis on Coastal Wetland and Conservation Areas, Pure Appl. Geophys., 173, 349-367, https://doi.org/10.1007/s00024-015-12352, 2016.

De Risi, R., Goda, K., Yasuda, T., and Mori, N.: Is flow velocity important in tsunami empirical fragility modeling?, Earth-Sci. Rev., 166, 64-82, https://doi.org/10.1016/j.earscirev.2016.12.015, 2017.

Duc, B. M. and Rodi, W.: Numerical Simulation of Contraction Scour in an Open Laboratory Channel, J. Hydraul. Eng., 134, 367-377, https://doi.org/10.1061/(ASCE)07339429(2008)134:4(367), 2008.

Edwards, C.: Thailand lifelines after the December 2004 Great Sumatra earthquake and Indian Ocean tsunami (SUPPL. 3), Earthq. Spectra, 22, S641-S659, https://doi.org/10.1193/1.2204931, 2006.

Eguchi, R. T., Eguchi, M. T., Bouabid, J., Koshimura, S., and Graf, W. P.: HAZUS Tsunami Benchmarking, Validation and Calibration, Pprepared for the Federal Management Agency through a contract with the Atkins, 1-48, available at: https://nws.weather.gov/nthmp/2013mesmms/abstracts/ 
TsunamiHAZUSreport.pdf (last access: 13 February 2020), 2013.

ESRI contributors: "Topographic" [basemap]. Scale Not Given, available at: https://www.arcgis.com/home/item.html?id= 30e5fe3149c34df1ba922e6f5bbf808f, last access: 12 August 2019a.

ESRI contributors: "World Imagery" [basemap]. Scale Not Given, "World Imagery", available at: https://www.arcgis.com/home/ item.html?id=10df2279f9684e4a9f6a7f08febac2a9, last access: 12 August 2019b.

Evans, N. L. and McGhie, C.: The Performance of Lifeline Utilities following the 27th February 2010 Maule Earthquake Chile, in: 9th Pacific Conference on Earthquake Engineering, Building an Earthquake-Resilient Society, 14-16 April 2011, Auckland, New Zealand, 2011.

Fritz, H. M., Petroff, C. M., Catalán, P. A., Cienfuegos, R., Winckler, P., Kalligeris, N., Weiss, R., Barrientos, S. E., Meneses, G., Valderas-Bermejo, C., Ebeling, C., Papadopoulos, A., Contreras, M., Almar, R., Dominguez, J. C., and Synolakis, C. E.: Field Survey of the 27 February 2010 Chile Tsunami, Pure Appl. Geophys., 168, 1989-2010, https://doi.org/10.1007/s00024-0110283-5, 2011.

Gehl, P. and D'Ayala, D.: Integrated Multi-Hazard Framework for the Fragility Analysis of Roadway Bridges, in: 12th International Conference on Applications of Statistics and Probability in Civil Engineering, ICASP12, 12-15 July 2015, Vancouver, Canada, 18, 2015.

Goff, J., Liu, P. L. F., Higman, B., Morton, R., Jaffe, B. E., Fernando, H., Lynett, P., Fritz, H., Synolakis, C., and Fernandoj, S.: Sri Lanka field survey after the December 2004 Indian Ocean tsunami (SUPPL. 3), Earthq. Spectra, 22, 155-172, https://doi.org/10.1193/1.2205897, 2006.

Graf, W. P., Lee, Y., and Eguchi, R. T.: New Lifelines Damage and Loss Functions for Tsunami, in: 10th U.S. National Conference on Earthquake Engineering, Frontiers of Earthquake Engineering, Earthquake Engineering Research Institute, 21-25 July 2014, Anchorage, USA, 2014.

Horspool, N. A. and Fraser, S.: An Analysis of Tsunami Impacts to Lifelines, GNS Sci. Consult. Rep. 2016/22, GNS Science, Lower Hutt, New Zealand, 1-87, 2016.

Istrati, D. and Buckle, I. G.: Effect of fluid-structure interaction on connection forces in bridges due to tsunami loads, in: Proceedings of 30th U.S.-Japan Bridge Engineering Workshop UJNR Panel on Wind and Seismic Effects, 21-23 October 2014, Washington, D.C., USA, p. 14, 2014.

Istrati, D., Buckle, I. G., Itani, A., Lomonaco, P., and Yim, S.: Large-Scale Fsi Experiments On Tsunami-Induced Forces In Bridges, in: 16th World Conference on Earthquake, 16WCEE, 9-13 January 2017, Santiago, Chile, p. 12, 2017.

Izquierdo, T., Fritis, E., and Abad, M.: Analysis and validation of the PTVA tsunami building vulnerability model using the 2015 Chile post-tsunami damage data in Coquimbo and La Serena cities, Nat. Hazards Earth Syst. Sci., 18, 1703-1716, https://doi.org/10.5194/nhess-18-1703-2018, 2018.

Kawashima, K. and Buckle, I.: Structural performance of bridges in the Tohoku-oki earthquake (SUPPL. 1), Earthq. Spectra, 29, S315-S338, https://doi.org/10.1193/1.4000129, 2013.

Kazama, M. and Noda, T.: Damage statistics (Summary of the 2011 off the Pacific Coast of Tohoku
Earthquake damage), Soils Found., 52, 780-792, https://doi.org/10.1016/j.sandf.2012.11.003, 2012.

Koks, E. E., Rozenberg, J., Zorn, C., Tariverdi, M., Vousdoukas, M., Fraser, S. A., Hall, J. W., and Hallegatte, S.: A global multihazard risk analysis of road and railway infrastructure assets, Nat. Commun., 10, 1-11, https://doi.org/10.1038/s41467-01910442-3, 2019.

Koshimura, S., Namegaya, Y., and Yanagisawa, H.: Tsunami fragility: a new measure to identify tsunami damage, J. Disaster Res., 4, 479-488, 2009.

Lagomarsino, S. and Cattari, S.: Seismic Performance of Historical Masonry Structures Through Pushover and Nonlinear Dynamic Analyses, Geotechnic, edited by: Ansal, A., Perspectives on European Earthquake Engineering and Seismology, 39, Springer Cham Heidelberg New York Dordrecht London, London, UK, 2015.

Lallemant, D., Kiremidjian, A., and Burton, H.: Statistical procedures for developing earthquake damage fragility curves, Earthq. Eng. Struct. D., 44, 1373-1389, https://doi.org/10.1002/eqe.2522, 2015.

Lin, S.-L., King, A., Horspool, N., Sadashiva, V., Paulik, R., and Williams, S.: Development and Application of the Real-Time Individual Asset Attribute Collection Tool, Front. Built Environ., 5, 1-14, https://doi.org/10.3389/fbuil.2019.00015, 2019.

Macabuag, J., Rossetto, T., Ioannou, I., Suppasri, A., Sugawara, D., Adriano, B., Imamura, F., Eames, I., and Koshimura, S.: Proposed methodology for defining optimal intensity measures for empirical tsunami fragility functions, in: 16th World Conference on Earthquake - WCEE, 9-13 January 2017, Santiago, Chile, 112, 2017

MLIT: Archive of the Great East Japan Earthquake Tsunami disaster urban reconstruction assistance survey, available at: http: //fukkou.csis.u-tokyo.ac.jp/ (last access: 1 June 2015), 2012.

Naito, C., Cercone, C., Riggs, H. R., and Cox, D.: Procedure for Site Assessment of the Potential for Tsunami Debris Impact, J. Waterw. Port Coast., 140, 223-232, https://doi.org/10.1061/(ASCE)WW.1943-5460.0000222, 2014.

Nakanishi, H., Black, J., and Matsuo, K.: Disaster resilience in transportation: Japan earthquake and tsunami 2011, Int. J. Disaster Resil. Built Environ., 5, 341-361, https://doi.org/10.1108/IJDRBE-12-2012-0039, 2014.

Nunn, M. E., Brown, A., Weston, D., and Nicholls, J. C.: Design of long-life flexible pavements for heavy traffic Prepared for Highways Agency, British Aggregate Construction, Transp. Res. Lab., TRL REPORT, Berkshire, UK, 1997.

NZTA: One Network Road Classification, New Zeal. Transp. Agency website, 2-3, available at: http://www.nzta.govt.nz/ projects/road-efficiency-group/onrc.html (last access: 21 January 2019), 2014.

OpenStreetMap contributors: Open Street Map, available at: https: //www.openstreetmap.org, last access: 15 October 2015.

Palliyaguru, R. and Amaratunga, D.: Managing disaster risks through quality infrastructure and vice versa, Struct. Surv., 26, 426-434, https://doi.org/10.1108/02630800810922766, 2008.

Paulik, R., Gusman, A., Williams, J. H., Pratama, G. M., Lin, S. lin, Prawirabhakti, A., Sulendra, K., Zachari, M. Y., Fortuna, Z. E. D., Layuk, N. B. P., and Suwarni, N. W. I.: Tsunami Hazard and Built Environment Damage Observations from Palu City after the September 282018 Sulawesi Earth- 
quake and Tsunami, Pure Appl. Geophys., 176, 3305-3321, https://doi.org/10.1007/s00024-019-02254-9, 2019.

Prasetya, G., Black, K., de Lange, W., Borrero, J., and Healy, T.: Debris dispersal modeling for the great Sumatra Tsunamis on Banda Aceh and surrounding waters, Nat. Hazards, 60, 11671188, 2012.

Puerto Creativo: Coquimbo y Tongoy Terremoto Tsunami Earthquake Drone, Chile, available at: https://www.youtube.com/ watch?v=B7mH8BV6RWQ (last access: 10 November 2016), 2015.

Puerto Creativo: Coquimbo y Tongoy Terremoto Earthquake Drone CALIDAD 4K, available at: https://www.youtube.com/watch? $\mathrm{v}=$ fCMzt5yrtLI\&t=740s, last access: 10 November 2016.

Scawthorn, C., Ono, Y., Iemura, H., Ridha, M., and Purwanto, B.: Performance of lifelines in Banda Aceh, Indonesia, during the December 2004 Great Sumatra earthquake and tsunami (SUPPL. 3), Earthq. Spectra, 22, 511-544, https://doi.org/10.1193/1.2206807, 2006.

Shoji, G. and Moriyama, T.: Evaluation of the Structural Fragility of a Bridge Structure Subjected to a Tsunami Wave Load, J. Nat. Disaster Sci., 29, 73-81, 2007.

Shoji, G. and Nakamura, T.: Development of damage functions on road infrastructures subjected to extreme ground excitations by analyzing damage in the 2011 off the pacific coast of tohoku earthquake, J. Disaster Res., 9, 121-127, 2014.

Sousa, L., Silva, V., Marques, M., Crowley, H., and Pinho, R.: Including multiple IMTs in the development of fragility functions for earthquake loss estimation, in: Second International Conference on Vulnerability and Risk Analysis and Management (ICVRAM) and the Sixth International Symposium on Uncertainty, Modeling, and Analysis (ISUMA), 13-16 July 2014, Liverpool, UK, 1716-1725, https://doi.org/10.1017/CBO9781107415324.004, 2014.
Suppasri, A., Mas, E., Charvet, I., Gunasekera, R., Imai, K., Fukutani, Y., Abe, Y., and Imamura, F.: Building damage characteristics based on surveyed data and fragility curves of the 2011 Great East Japan tsunami, Nat. Hazards, 66, 319-341, https://doi.org/10.1007/s11069-012-0487-8, 2013.

Tang, A., Ames, D., McLaughlin, J., Murugesh, G., Plant, G., Yashinsky, M., Eskijian, M., Surrampalli, R., Murthy, P. A. K., Prasad, M., and Gandhi, P.: Coastal Indian lifelines after the 2004 Great Sumatra earthquake and Indian Ocean tsunami (SUPPL. 3), Earthq. Spectra, 22, 607-639, https://doi.org/10.1193/1.2206089, 2006.

USGS: M 8.3 - $48 \mathrm{~km}$ W of Illapel, Chile, available at: https://earthquake.usgs.gov/earthquakes/eventpage/us $20003 \mathrm{k} 7 \mathrm{a} /$ technical (last access: 24 July 2019), 2015.

Williams, J. H.: Illapel Tsunami 2015 Road Dataset, figshare, https://doi.org/10.6084/m9.figshare.11839323.v1, 2020.

Williams, J. H., Wilson, T. M., Horspool, N., Lane, E. M., Hughes, M. W., Davies, T., Le, L., and Scheele, F.: Tsunami impact assessment: development of vulnerability matrix for critical infrastructure and application to Christchurch, New Zealand, Nat. Hazards, 96, 1167-1211, https://doi.org/10.1007/s11069-01903603-6, 2019.

Ye, L., Lay, T., Kanamori, H., and Koper, K. D.: Rapidly Estimated Seismic Source Parameters for the 16 September 2015 Illapel, Chile $M_{\mathrm{W}} 8.3$ Earthquake, Pure Appl. Geophys., 173, 321-332, https://doi.org/10.1007/s00024-015-1202-y, 2015. 